\title{
Toward a classification of discourse patterns in asynchronous online discussions
}

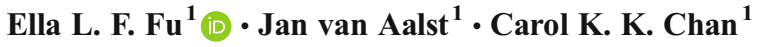

Received: 30 August 2015 / Accepted: 24 October 2016/Published online: 5 November 2016

(C) The Author(s) 2016. This article is published with open access at Springerlink.com

\begin{abstract}
The goal of this study was to develop a classification for a range of discourse patterns that occur in text-based asynchronous discussion forums, and that can aid in the distinction of three modes of discourse: knowledge sharing, knowledge construction, and knowledge building. The dataset was taken from Knowledge Forum ${ }^{\circledR}$ databases in the Knowledge Building Teacher Network in Hong Kong, and included three discussion views created for different classes: Grade 5 Science, Grade 10 Visual Arts, and Grade 10 Liberal Studies. We used a combination of qualitative coding and narrative analysis as well as teachers' understanding of online discourse to analyze student discussions. Nine discourse patterns were identified. These patterns revealed a variety of ways in which students go about their collaborative interactions online and demonstrated how and why students succeed or fail in sustaining collaborative interactions. This study extended the three modes of online discourse and developed different discourse patterns, which are efforts to provide instructional guidance. The implications of supporting productive discourse and the enactment of CSCL innovations in classrooms are discussed.
\end{abstract}

Keywords Knowledge building $\cdot$ Discourse analysis $\cdot$ Discourse patterns $\cdot$ Asynchronous discussion forum $\cdot$ Text chat

\section{Introduction}

Collaborative interactions that occur during learning are at the core of computer-supported collaborative learning (CSCL). Developing an in-depth understanding of the nature of

Ella L. F. Fu

ellafulf@gmail.com

Jan van Aalst

vanaalst@hku.hk

Carol K. K. Chan

ckkchan@hku.hk

1 The University of Hong Kong, PokfulamRoad, Hong Kong, China 
collaborative interactions contributes to not only theory development, but also to the enactment of CSCL innovations in mainstream classrooms (Koschmann et al. 2005; Meier et al. 2007; Rummel et al. 2009). However, much research has shown a noticeable problem with this enactment: use of CSCL technology fails to promote the kind of collaborative interactions envisaged by the learning theories on which the technological design is based. This is evidenced by records of student discourse captured in online discussion forums; sustained on-topic discussions (Guzdial and Turns 2000), convergent processes (Hewitt 2001), and discussions in which subsequent posts respond to each other have rarely been found (Lipponen et al. 2003; Hakkarainen 2003a; Palmer et al. 2008; Peters and Hewitt 2010; Wise et al. 2014). Although online discussion forums are increasingly used in classrooms to support joint cognitive activities, students often resort to sharing personal opinions and fragmented information (Stahl et al. 2006).

Researchers have noted another problem related to the enactment of classroom innovations. Brown and Campione (1996) used the term lethal mutation to describe a widespread problem in educational reform; specifically, that the learning principles used to guide the design of classroom innovations are lost when designs are implemented. Bereiter (2002a) attributed this problem to the tendency toward proceduralization, in which classroom innovations degenerate into a set of ritualistic activities and the completion of these activities replaces the learning goal. This problem suggests that teachers do not have a deep understanding of classroom innovations, and therefore focus on adopting the surface procedure. To disseminate CSCL innovations, Hakkarainen (2009) suggested the need for a more comprehensive understanding of the dynamic relationships between technology, pedagogy, and social practices. We propose that it is important to tap into teachers' understanding of students' CSCL discourse in relation to principles of classroom innovations.

The goal of this study was to develop a classification of asynchronous online discourse patterns that both theorists and practitioners could use to evaluate the alignment of discourse with a theoretical framework. For theorists, this may aid in identifying conceptual contrasts between, for example, argumentation and explanation-oriented discourse. In the field, there has been considerable interest in the relationships between these modes of discourse (Andriessen 2006; Mu et al. 2012; Osborne and Patterson 2011; Stegman et al. 2007). For teachers, we propose that it is useful to be able to recognize discourse patterns that are productive and counterproductive for meeting specific instructional goals. For example, when a teacher poses a question, many students may respond individually, without an uptake of the ideas necessarily following. Discourse patterns have been studied extensively for both face-to-face discourse in classrooms and asynchronous online discourse (Chin 2007; Dawes 2004; Howe and Abedin 2013; Mercer and Littleton 2007). The extent to which online discourses are ranging from unproductive to productive patterns would indicate how and whether learners are making use of the assumed affordances of online learning environments.

This study draws on Bereiter and Scardamalia's theory of knowledge building, which describes the creation and improvement of new ideas and adding value to a community (Scardamalia 2002; Scardamalia and Bereiter 2014). The starting point for its analysis is the framework proposed by van Aalst (2009), which distinguishes between knowledge sharing, knowledge construction, and knowledge building/creation discourses, and highlights the similarities and differences among the major learning theories in CSCL. Knowledge sharing is underpinned by an understanding of learning as the transmission of ideas. Knowledge construction is involved in problem solving and construction of knowledge. Knowledge building/creation involves a focus on the community rather than a small group, and in addition 
to knowledge sharing and construction, it involves sustained inquiry, pursuit of communal goals and communal advance. In the present study, we took a more inductive approach to further elaborate the framework, analyzing a more representative sample of online work covering multiple school subjects, student achievement levels, and grade levels. The data came from a large professional development project, the Knowledge Building Teacher Network, which aims to address the new goals of curriculum reform in Hong Kong (Chan 2011).

\section{Knowledge building, implementation, and discourse}

\section{Knowledge building}

Knowledge building is a "coherent effort to initiate students into a knowledge creation culture. ... It involves students not only developing knowledge-building competencies but also coming to see themselves and their work as part of the civilization-wide effort to advance knowledge frontiers" (Scardamalia and Bereiter 2006, pp. 97-98). It aims to transform the goal of schooling from learning to creating knowledge; emphasizes student agency, idea improvement, and community knowledge; and is supported by an online discussion forum known as Knowledge Forum ${ }^{\circledR}(\mathrm{KF})$. Knowledge building does not offer classroom procedures or scripts for its enactment in classrooms. Rather, Scardamalia (2002) developed an interconnected system of 12 principles to characterize the socio-cognitive and technological dynamics of knowledge building. The principles are: (1) real ideas, authentic problems; (2) idea diversity; (3) improvable ideas; (4) epistemic agency; (5) community knowledge, collective responsibility; (6) democratizing knowledge; (7) symmetric knowledge advance; (8) pervasive knowledge building; (9) constructive uses of authoritative sources; (10) knowledge-building discourse; (11) concurrent, embedded, transformative assessment; and (12) rise above. There are many benefits to using principles to elaborate the learning goals and concepts of learning theory. In practice, principles facilitate the enactment of classroom innovations. Brown and Campione (1996) suggested that if a pedagogical design is based on learning principles, researchers should specify what the principles are and explain how they can inform the practices of teachers and school administrators. Learning principles also provide a blueprint for the cultivation of a new classroom culture and the transformation of teachers' epistemological beliefs (Zhang 2010). They can engage teachers in a principle-based understanding of classroom innovations and support teachers in going beyond simply adopting the surface procedures of innovations (Hong and Sullivan 2009).

Knowledge building has been successfully implemented by researchers in many contexts to enhance idea improvement and domain knowledge (Chan 2012; Hong et al. 2016) including elementary science (Zhang et al. 2007), graphical literacy (Gan et al. 2010), mathematics (Moss and Beatty 2006, 2010), geography (Lee et al. 2006), clothing design (Lahti et al. 2004; Seitamaa-Hakkarainen et al. 2001), teacher education (Erkunt 2010; Chen and Hong 2016; Laferriere et al. 2006), vocational education (de Jong et al. 2002), and health care (Lax et al. 2006; Mylopoulos and Scardamalia 2008). Furthermore, many studies have shown that students show significant improvements in their scientific understanding, and can engage in scientific inquiry (Hakkarainen 2003b), community knowledge advancement (Zhang et al. 2007), the reading practices of scientific communities (Zhang and Sun 2011), and the use of academic words (Sun et al. 2010) while participating in interventions that include knowledge building. Studies have also shown that knowledge-building principles are conducive to the 
enactment of classroom innovations. Zhang et al. (2011) identified how knowledge-building principles played a role in a design-based approach with a direction for the development of innovative classroom practice in a school-wide knowledge-building project. Students can also use knowledge-building principles. van Aalst and Chan (2007) described an electronic portfolio assessment approach in which the principles were given to students as selfassessment criteria to identify and reflect their knowledge-building episodes in KF. The assessment approach has been used in a number of studies as a tool to align learning, collaboration, and assessment (Lee et al. 2006; Zhang et al. 2007; Zhang et al. 2009).

Although a wealth of research has demonstrated the feasibility and benefits of knowledge building, most studies have been conducted either with the direct involvement of researchers in classroom teaching or by veteran knowledge-building teachers. When working with the teachers in the Knowledge Building Teacher Network, we developed insights into how ordinary teachers struggled to implement knowledge building. The network fostered a hybrid culture of teacher-researcher collaboration in which the teachers and researchers had weekly meetings to design and improve teaching practices (Chan 2011). When discussing pedagogical improvement, the teachers spontaneously referred to their students' online work. Therefore, they were guided to co-investigate their students' online discourse through a framework comprising the three modes of discourse and knowledge-building principles. For example, when an online discourse showed that the students had engaged in the sharing of factual knowledge, the teachers referred to the principle of constructive use of authoritative sources to emphasize the need to scaffold students toward interpreting and explaining information, rather than merely locating relevant information. Co-investigation into the online discourse not only generated feedback for the teachers to improve their teaching practices, but also became a method for them to deepen their principle-based understanding of knowledge building.

\section{Nature of online discourse and knowledge-building discourse}

CSCL research focuses on understanding the practice of collaborative meaning making, and the manner in which it is mediated by classroom innovations (Koschmann 2002; Puntambekar et al. 2011). Therefore, most studies involving the use of asynchronous text-based discussion forums have examined student collaborative interactions through the analysis of online discourse. The CSCL community has developed numerous ways to analyze online discourse, mainly based on two traditions: socio-cognitive and interpretive. Studies following the socio-cognitive tradition have often used content analysis, which is also known as verbal analysis or a coding-andcounting approach, to segment online discourse into standardized units and to assign each unit to a theory-informed and mutually exclusive coding category (Chi 1997; De Wever et al. 2006; Krippendorff 2004; Strijbos et al. 2006). For example, Gressick and Derry (2010) illustrated the concept of emergent leadership skills using six categories: affective, argument, seeking input, knowledge contribution, organizational moves, and topic control. Arvaja (2007) analyzed online discourse with three sets of coding schemes: thematic structure, communicative functions, and contextual resources. Hmelo-Silver (2003) used four categories to capture the coconstruction of a joint problem space: knowledge, metacognition, interpretation, and collaboration. As for argumentation, Baker et al. (2007) developed seven categories to analyze its social and cognitive aspects, and Weinberger and Fischer (2006) segmented its process into four dimensions: participation, epistemic, argumentative, and social.

Numerous studies of knowledge building have used content analysis to evaluate the cognitive aspects of online discourse. Hakkarainen (2003b) defined fact- and explanation- 
seeking questions and proposed that the latter entailed a more sophisticated epistemology. Hakkarainen and Sintonen (2002) suggested that more specific, subordinate questions formulated on the basis of an initial research question could drive the knowledge advancement processes. Chan et al. (1997) developed a knowledge-building scale that indicated the level of knowledge-processing activities in use when students learned conflicting scientific information, adapted for analyzing depth of inquiry (Lee et al. 2006). Hakkarainen (2003b) similarly classified student-generated explanations into five levels, starting with isolated facts and ending with coherent scientific explanations. Chuy et al. (2011) developed a knowledgebuilding discourse scheme that was adopted by other studies (Chen et al. 2015; Resendes et al. 2015) and included six major categories: theorizing, asking questions, obtaining information, working with information, synthesizing, and furthering discussions. The knowledge-building principles were also operationalized and used as a coding scheme to assess the extent to which students engaged in knowledge-building activities (Zhang et al. 2007). van Aalst (2009) developed seven coding categories and mapped the coding to three modes of online discourse. The coding categories are explained in the methodology section.

Although content analysis has revealed important dimensions and characteristics of online discourse, numerous researchers have pointed out its limitations. Content analysis findings have described the occurrences of various coding categories, but such occurrences do not reveal how collaborative learning unfolds over time (Strijbos et al. 2006; Suthers 2006). Moreover, as the segmentation process ignores the semantics of discussion and the signals of collaboration (Çakır et al. 2009; Stahl 2002), the situational and contextual information that indicates how and why an utterance is produced is obscured (Kumpulainen and Mutanen 1999; Suthers et al. 2010). Therefore, Hmelo-Silver (2003) suggested the use of multiple methods to examine the multifaceted online discourse, and Stahl (2011) proposed using a group as the unit of analysis when attempting to understand how a group as a whole constructs knowledge and engages in intersubjective meaning making.

Many CSCL studies have been premised on the interpretive tradition and used qualitative analyses but mostly in small group settings. Roschelle and Teasley's (1994) pioneering study of CSCL used conversation analysis to explore the structure of two students' online discourse during the process of collaborative problem solving. Conversation analysis examines the details of microsecond transcriptions of talk-in-interaction (ten Have 2007). This approach is a useful tool for exploring collaborative processes because the meaning of utterances is indexical, elliptical, and projective according to the context in which they occur (Stahl 2003). Koschmann et al. (2005) used this kind of analysis to uncover the sequential organization of both online and offline discourse in a problematizing move. Çakır et al. (2009) used conversation analysis to trace how a small group made use of online objects and discourse to coordinate their joint activities. Suthers and Medina (2011) created contingency graphs to track how small groups engaged in problem solving by drawing on multiple data such as verbal, nonverbal, and representational objects in online platform. Findings generated from the interpretive tradition mostly have implications for dyad and small-group online interactions in short durations of a few minutes. Much less is known about how a classroom community engages in collaborative interactions over a few months.

A number of studies of knowledge building have also used qualitative approaches to analyze online discourses. They have focused on using excerpts of discourse to illustrate the concepts constituting their research focus, such as determining the situations in which students take a constructive approach to reading (Scardamalia et al. 1996), how changes in pedagogy and learning environments affect discourse writing and scientific understanding (Caswell and Bielaczyc 2002), 
and how pre-service teachers are acculturated into a knowledge-building community (Chan and van Aalst 2006). However, these studies have not focused on exploring the process of online interactions. Studies have adopted a mixed method approach to partially address this question, using qualitative analysis to complement quantitative analysis and uncover the nature of the quantitative differences (Jeong et al. 2014). For example, after quantitative analysis demonstrates that students have successfully engaged in some kinds of knowledge-building activity, qualitative discourse analysis is used to present a series of online messages to illustrate how ideas are developed during online interactions (van Aalst and Truong 2011), how knowledge-building principles manifest in online discourse (Zhang et al. 2007), and how students exercise promisingness judgments with the help of an online tool (Chen et al. 2015). However, no study of knowledge building thus far has been entirely dedicated to systemically exploring how different types of discourse patterns are developed during online discussions.

In this study, we used both qualitative coding and interpretive narrative analysis to gain a deeper understanding of how a classroom community engages in online discussions over a few months. To build on what is known about the characteristics of online discourse, we adapted the coding scheme of content analysis developed by van Aalst (2009). We aimed to develop discourse patterns and show the variety of ways in which students go about their collaborative interactions online. To enhance the pedagogical value of this study, we identified the discourse patterns with the involvement of teachers in the Knowledge Building Teacher Network. During weekly meetings with teachers, the three modes of discourse developed by van Aalst (2009) were introduced to teachers as a framework for discussing their students' online work. To devise pedagogical supports, teachers often analyzed the quality of students' arguments and explanations by using the three modes of discourse. Working with teachers, we developed a deep insight into teachers' principle understanding of knowledge building, their understanding of CSCL discourse, and their difficulties with articulating the processes of sustained discussions.

The study began by building on a framework comprising three modes of online discourse (van Aalst 2009). The framework has previously been applied in approximately 230 classes to examine the quality of online discourse and change for the Knowledge Building Teacher Network between 2006 and 2010 (Chan 2011) and to explore how the three modes of discourse could be identified in different subjects and grade levels. It is important to note that we did not merely replicate earlier research (van Aalst 2009; Chan 2011); rather, we further developed the framework by analyzing discourse patterns that captured the various ways in which students talk online and that illustrated each of the three modes of discourse. The research goal of the current study was to identify and characterize different types of discourse patterns in the KF database, and to examine how they may be distinguished using the framework of knowledge sharing, knowledge construction, and knowledge building. We also explored how the identified discourse patterns may also be applicable to other databases to explore their usability.

\section{Methods}

\section{Research context and participants}

The dataset for this study included three KF discussion views (spaces) of three different classes from the Knowledge Building Teacher Network project. KF is a computer-supported collaborative learning environment that supports knowledge-building collective inquiry 
(Scardamalia 2004), reframes typical classroom discourse patterns, and gives students opportunities to jointly design for knowledge creation (Scardamalia and Bereiter 1993). Figure 1 shows an example of a discussion view. Messages are written in notes (squares) and posted on a discussion view. The clusters of notes connected by arrows are discussion threads.

Although the three modes of discourse framework was applied in approximately 230 classes, we only conducted a preliminary analysis. The current study selected three discourse views for in-depth analysis according to two purposive sampling steps. First, we ran statistical analyses using KF server log data for 75 classes which participated in the project in 2010 2011. The server log data indicated the number of notes written and read in each class. The second step involved teachers' comments on the quality of the databases. Classes that produced many notes were selected, and their databases were presented during teacher meetings. The teachers discussed the quality of online discourse through the lens of the three modes of discourse. After obtaining teacher perspectives, we selected three discussion views that showed variation in discourse quality, subject area, grade level, and teacher experience in knowledge building. The selected views did not necessarily contain the very best examples of knowledge building in the project, but showed variations in discourse patterns in the Knowledge Building Teacher Network project, and thus provided multiple examples that could enhance the usability of the qualitative research findings (Schrire 2006).

Table 1 shows the server log data from the three selected views, including the number of notes written, the number of notes revised, the number of notes which referred to other notes, the percentage of notes linked to other notes, the percentage of notes with keywords tagged to assist searches within the database, and the percentage of notes read by other students over the course of the discussion period. One Grade 5 class had 38 students who discussed the topics of matter and power which made up the science view. During the seven week period, each student created an average of 8.7 notes, with a total of 346 notes created. One Grade 10 class of 19 students discussed the topic of community art (that is, street art), and created the visual arts view. During the four week period, each student created an average of 15.4 notes, with a total of 292 notes created. Participation in terms of note creation in these views was satisfactory, compared with other studies of knowledge building that involved students in similar grades (van Aalst 2009; Zhang et al. 2007). Finally, two Grade 10 classes totaling 82 students shared a database to discuss the topic of political engagement, and actively engaged in that discussion

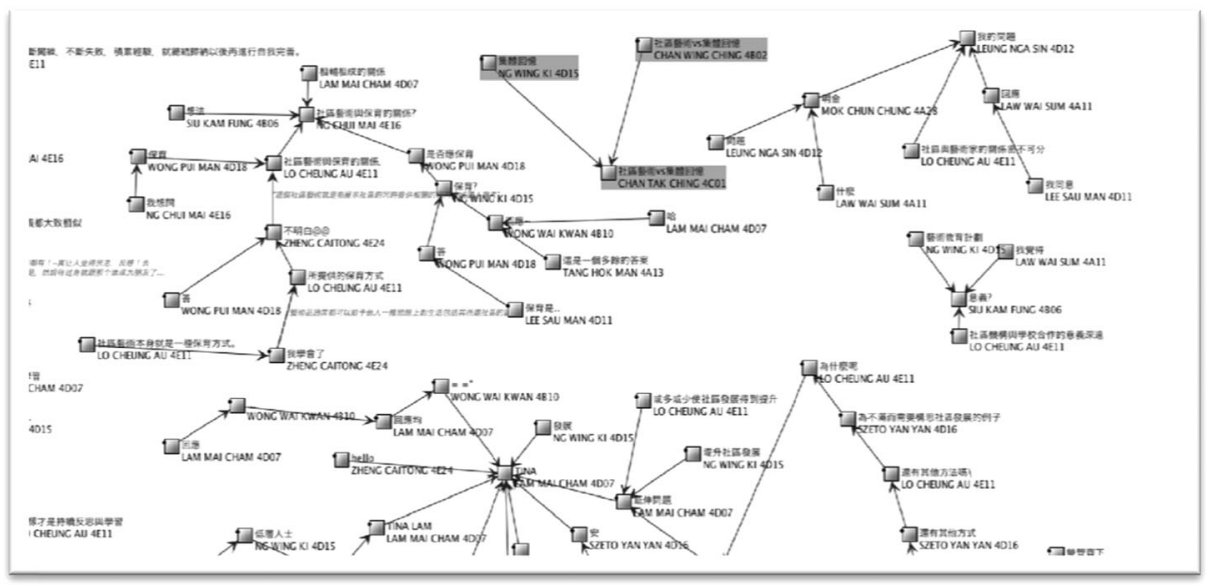

Fig. 1 A discussion view in knowledge forum 
Table 1 Server-log data of the three selected views during the discussion period

\begin{tabular}{|c|c|c|c|c|c|c|}
\hline & \multicolumn{2}{|c|}{ Grade $5(n=38)$ science } & \multicolumn{2}{|c|}{$\begin{array}{l}\text { Grade } 10(n=19) \\
\text { visual arts }\end{array}$} & \multicolumn{2}{|c|}{$\begin{array}{l}\text { Grade } 10(n=82) \\
\text { liberal studies }\end{array}$} \\
\hline & Mean & SD & Mean & SD & Mean & SD \\
\hline No. of notes created & 8.7 & 5.1 & 15.4 & 9.11 & 1.5 & 1.63 \\
\hline No. of revisions & 0.8 & 1.8 & 5 & 11.8 & 0.3 & 1 \\
\hline No. of reference in notes & 0.2 & 0.5 & 3.6 & 7.8 & 0.1 & 0.4 \\
\hline$\%$ of notes linked & 80.9 & 30.8 & 91 & 9.5 & 76.4 & 41.4 \\
\hline$\%$ of notes with keywords & 39.4 & 30.13 & 6.5 & 13.4 & 9.2 & 27.01 \\
\hline$\%$ of notes read & 28.0 & 21.9 & 80.9 & 22.8 & 30 & 24.2 \\
\hline
\end{tabular}

over the course of 10 weeks. Based on their discussion, the teacher and students developed another view, which included some large note clusters from an earlier view, to deepen their discussion. The second view with 126 notes was included in the study in spite of the small number of notes per student because teachers suggested this view contained good discussion. In sum, 764 notes were included in the dataset. The students mainly wrote in Chinese.

\section{Qualitative analysis}

Qualitative analysis in this study was assisted by Atlas.ti (Computer Assisted Qualitative Data Analysis Software). Due to the complex physical structure of the CSCL discussion threads, qualitative analysis involved three components - thematic analysis, qualitative coding, and narrative analysis - which are described below.

\section{Component 1: Thematic analysis}

The purpose of thematic analysis was to identify the main themes discussed by the students, and to preprocess the data for subsequent analyses. The unit of analysis was an inquiry thread (Zhang et al. 2007), which is typically a collection of notes that addresses a problem or discusses a theme. The discussion views were parsed into inquiry threads, with each inquiry thread having a main theme. To preserve the sequential order of the notes in an inquiry thread, the notes were placed in chronological order, sorted first by their physical thread structure, and then by their time of creation (Wise and Chiu 2011). Forty inquiry threads were identified, including 15 in the Grade 5 Science (G5S) class, 16 in the Grade 10 Visual Arts (G10VA) class, and nine in the Grade 10 Liberal Studies (G10LS) class.

\section{Component 2: Qualitative coding}

Having identified the main themes via the inquiry threads, the goal of qualitative coding was to code the discourse within each inquiry thread for different discourse dimensions. Usually, in content and verbal analysis, a small number of codes is generated and applied to small and uniform units, such as idea units, questions, or computer notes (Chi 1997; Krippendorff 2004; Strijbos et al. 2006). After parsing the discourse into these units, a single code is applied to a unit. In this study, the unit of analysis was much larger - an entire inquiry thread - so we employed a more flexible approach, in which both the number of codes applied and the amount of material to 
which a code was applied were variable. We used this approach because the discourse dimensions could not be captured by a standardized coding unit. For example, we expected that the dimension of "explanation" would manifest within one note, while "meta-discourse" would manifest in multiple notes; therefore, the material to which the codes were applied ranged from phrases, sentences, and notes to multiple notes, depending on the meaning of a given sub-code. The guiding rule was that a code should include sufficient text to provide enough information to be meaningful and understandable (Coffey and Atkinson 1996). Moreover, codes could be overlapping, nested, or embedded within one another (Saldaña 2009). Rather than coding out of context, we assigned each code to a text segment within each inquiry thread. Each text segment was coded in relation to the segments preceding and following it.

We started with van Aalst's (2009) coding scheme, which comprises seven dimensions ("agency," “community," "idea," “information," "linking," "meta-discourse," and "question"), and further developed these definitions. For example, we conceptualized "ideas" and "questions" according to notions of epistemological inquiry (Chan et al. 1997; Hakkarainen 2003b); "information" was related to epistemic cognition (Chinn et al. 2011); "agency" was related to meta-knowing (Kuhn 2005) and shared regulation (Järvelä and Hadwin 2013); "community" and "meta-discourse" were premised on progressive problem solving and rise above (Scardamalia and Bereiter 2014); and "social-affective-communal" was related to social presence (Rourke et al. 1999). "Linking" referred to the functionality of KF. The seven discourse dimensions were also named as main codes, and operationalized by developing sub-codes. The coding process started with the list of sub-codes in van Aalst's (2009) study, and was guided by the revised definitions of the discourse dimensions.

The coding was conducted by an iterative process involving theory- and data-driven approaches to enhance the coding list's compatibility with the empirical data (Boyatzis 1998) and to restrain the coder from imposing predefined codes thereon (Hennink et al. 2011). Table 2 describes the discourse dimensions and sub-codes.

\section{Component 3: Narrative analysis}

Guided by the qualitative coding results and thematic narrative analysis (Polkinghorne 1988), a well-established qualitative analysis method emphasizing the process of interactions, we identified various discourse patterns. According to Riessman (2008), thematic narrative analysis focuses mainly on content (i.e., what is said, not how), genre, and the broad context. We developed different online discourse patterns to describe students' various collaborative interactions, resulting in the characteristics of knowledge-sharing, knowledge-construction, or knowledge-building discourses.

The unit of analysis was a narrative unit including at least five notes that were physically connected within an inquiry thread. Shorter note clusters, based on our observations, did not generally involve meaningful student discussions. Narrative units typically are manifested in three forms. First, a narrative unit can be a small note cluster comprising at least five notes. Figure 2, shows two such units; a triangle represents the seed note (i.e., the first message in the cluster), rectangles represent build-on notes, and arrows represent the build-on sequence direction. In small note clusters, most notes are linked directly to the seed note.

The second form is a sustained linear physical thread. Figure 3 shows three narrative units in two note clusters. We analyzed only the seed notes and build-on notes indicated by solid black rectangles, and excluded the build-on notes indicated by hollow rectangles, because our goal was to track the development and evolution of sustained interactions. The left note cluster contains one narrative unit; the right contains two units starting from a single seed note. 
Table 2 Summary of the descriptions of the discourse dimensions and sub-codes

\begin{tabular}{|c|c|}
\hline Codes & Brief description \\
\hline Social-Affective-communal & Socio-affective-emotional -aspect of the interactions \\
\hline Agreement & Acknowledging and expressing agreement on an idea \\
\hline Compliment & Showing gratitude for another's contribution \\
\hline Different views & Raising different views /Expressing disagreement over an idea \\
\hline Disclose personal issue & Disclosing personal issues such as like/dislike, prior experience, or personal philosophy \\
\hline Disclose vulnerability & Admitting mistakes or acknowledging weaknesses \\
\hline Emotion & Expressing feeling by emoticons, punctuation, or conspicuous capitalization \\
\hline Humor & Engaging in such social activities as teasing, joking, irony, sarcasm, or kidding \\
\hline Salutation & Expressing social activities such as greeting, closure, or self-introduction \\
\hline Seeking views\# & Inviting contributions from others \\
\hline Shared experience & Referring to past or future joint activities \\
\hline Team spirit & Expressing a sense of belonging or commitment to the group \\
\hline Information & Use of information in interaction and collaboration \\
\hline Information stated & Information stated with no explanation or elaboration \\
\hline Information introduced\# & Information introduced not -relevant to - the problem at hand \\
\hline Information source & Discussing issues relating to the source of knowledge \\
\hline Information interpreted\# & Using information to construct a solution to the problem at hand \\
\hline Question & Asking Questions -and engagement in inquiry processes \\
\hline Fact seeking\# & Asking close-ended questions seeking definite answers \\
\hline Clarification\# & Clarifying ambiguities arising from previous ideas \\
\hline Explanation seeking\# & Asking open-ended questions seeking elaborative explanations \\
\hline Sustained & Specific questions formulated based on the previous idea \\
\hline Codes & Brief Description \\
\hline Idea & Focus on putting forth and development of ideas \\
\hline Fact\# & Stating brief facts \\
\hline Opinion\# & Making subjective judgments \\
\hline Analogy & Using analogical reasoning to develop ideas \\
\hline Conjecture\# & Using personal theories to construct a partial explanation \\
\hline Elaboration\# & Elaborate and build on ideas often including source materials - \\
\hline Explanation\# & Construct explanation to improve ideas using principles and source materials \\
\hline Summary/synthesis & Summarizing ideas from multiple notes to synthesize and rise above \\
\hline Linking & Referring to Knowledge Forum affordances \\
\hline Bridging knowledge & Linking to Web materials to enrich community knowledge \\
\hline Referencing & Using the reference function in KF to quote others' ideas \\
\hline Agency & Task and social regulation processes \\
\hline Metacognitive knowing & $\begin{array}{l}\text { Expressing what students currently know, need, or do not need to know, or the reasons } \\
\text { behind their knowledge }\end{array}$ \\
\hline Metacognitive knowing evaluation & Commenting on the quality or validity of another's idea \\
\hline Metastrategic knowing & Scaffolding others to construct a more coherent explanation \\
\hline Metastrategic knowing evaluation & $\begin{array}{l}\text { Guarding the question-and-explanation exchange processes against unintentional } \\
\text { digression }\end{array}$ \\
\hline Shared regulation & Repairing the conversations and sustaining the willingness to learn \\
\hline Community: Meta-discourse & Discourse used to raise the bar of collective knowledge \\
\hline Lending community support\# & $\begin{array}{l}\text { Meta-discourse efforts looking back at what has been discussed and Proposing to move } \\
\text { to a new stage of inquiry }\end{array}$ \\
\hline Problem analysis \& synthesis & Analyzing a problem and synthesize from a higher-level perspective \\
\hline Problem transfer & Transferring a question from one context to another \\
\hline
\end{tabular}

Codes marked \# were in the van Aalst's (2009) original coding scheme, and redefined for this study; the other codes were developed for this study 
Fig. 2 Small note clusters

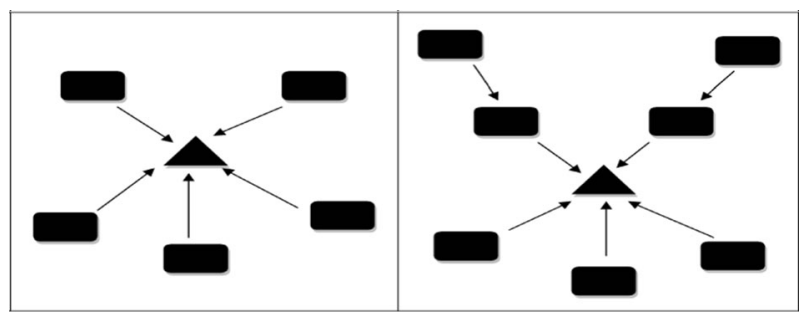

The third narrative unit form manifests as a sub-thread that branches out from a sustained linear thread. Figure 4 shows two units - one series of eight notes (notes 1-8) forming a sustained linear physical thread, and one series of five notes (notes 4 and 11-14) forming a sub-thread. The two units were analyzed separately; as above, the notes indicated by hollow rectangles were excluded.

Figure 5 shows a unit of analysis. The long bar on the right, starting from line 1, indicates the discourse pattern (knowledge sharing: fact-oriented discourse). Each note's first sentence denotes its title, then its writer and date. The short bar on the right labels the main code and sub-code (e.g., "Question: Explanation-seeking"). Most notes were in the "information" and "question" dimensions. Qualitative coding makes it clear that students were engaging in the sharing of factual knowledge in this unit. This example is described in the Finding section of this paper, under "Fact-oriented discourse".

After identifying the unit of analysis, the first author studied each narrative unit individually, focusing on the coding results - i.e., which main and sub-codes the unit contained. Focusing on the sub-codes' chronological order, the author described each unit thoroughly to indicate whether and how students' ideas were developed in the course of interactions. The sub-codes helped the analysis but did not determine the discourse patterns. Even with some high-level ideas, the discourse might not have been developed because students might have written an elaborative explanation based on their reading, without relating it to the ongoing conversation. Finally, narrative units sharing similar descriptions were grouped, and different groups then tied to concepts drawn from previous studies on student discourse to further develop those descriptions.

\section{Managing subjectivity}

We took numerous actions to manage subjectivity at each analytical stage. In thematic analysis, $30 \%$ of inquiry threads were reviewed by a colleague (not one of the coauthors)

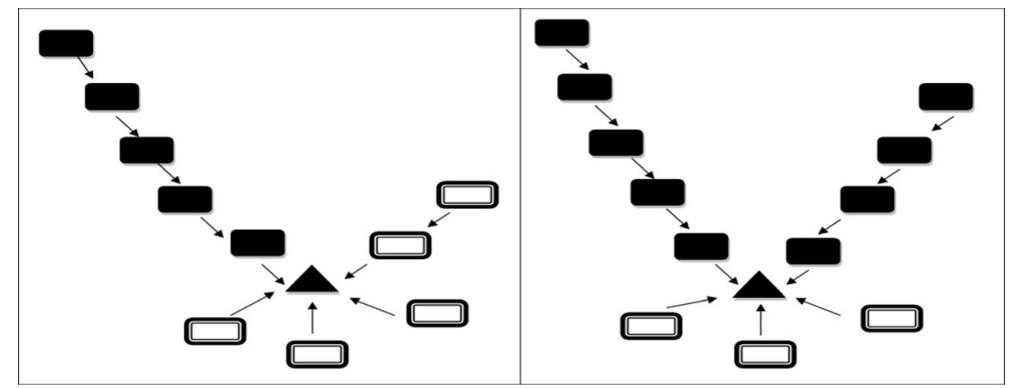

Fig. 3 Sustained linear physical threads 


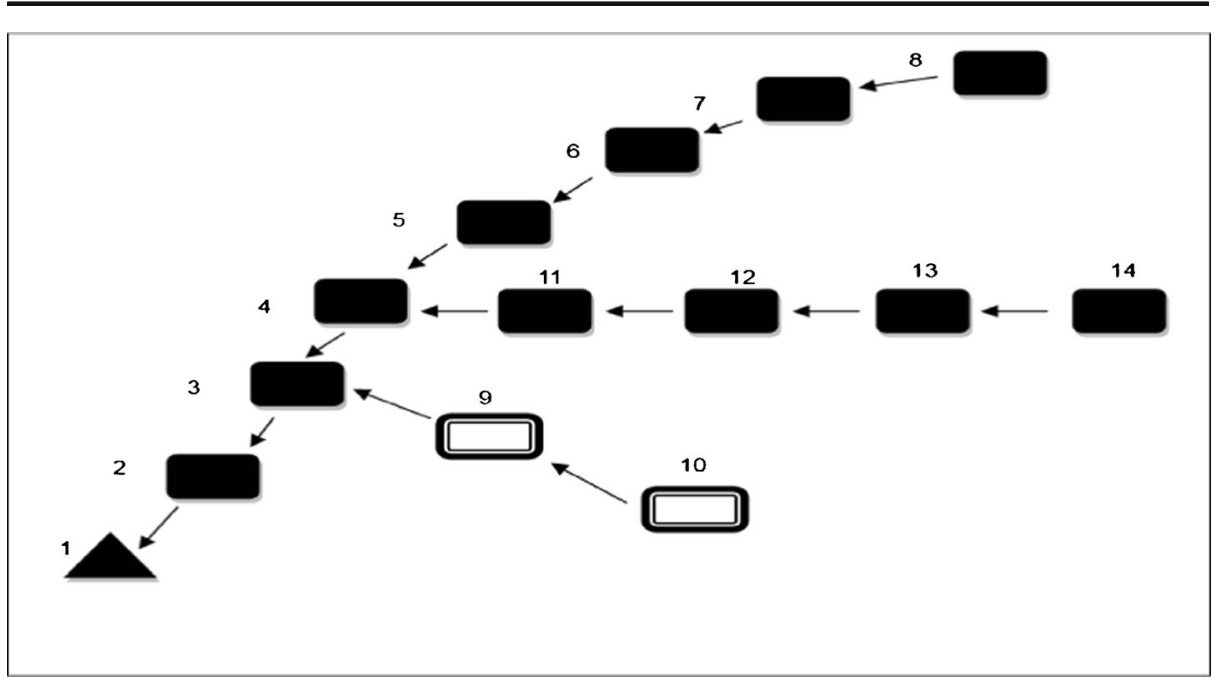

Fig. 4 Sustained linear physical thread and sub-thread

with a similar level of qualitative coding experience, who suggested such improvements as renaming some inquiry threads and identifying notes that could be assigned to more than one inquiry thread. In the qualitative coding, the main and sub-code definitions and initial coding results were reviewed by another colleague (not one of the coauthors) in the research group with experience analyzing KF data, who found some new sub-code definitions too general; accordingly, some new sub-codes were merged and conceptually redefined. After the first author used the revised code list to reanalyze the dataset, the colleague then randomly selected and examined three coded occurrences per sub-code, found the revised code list accurately reflected the empirical data, and made no further suggestions. After narrative analysis, 13 initial discourse patterns were presented to the entire research group for critical feedback. Several difficult-to-distinguish patterns were eliminated and the final set of discourse patterns was created. These patterns were also presented at an international conference. In sum, the findings are not the result of a single researcher's inferences, but reflect a collaborative process to revising and justifying inferences until further refinements seemed unnecessary. This strategy has often been used in qualitative research to safeguard against researcher bias (Çakır et al. 2009; Roth 2005).

\section{Results}

\section{Qualitative coding}

Table 3 shows the summary of the frequency of the main codes and sub-codes. The most frequently assigned dimensions were "idea," "social-affective-communal," and "question." With "idea" representing $45.87 \%$ of the total discourse, including more than half of those in the G5S (53.95\%) and G10LS classes (58.75\%). Table 3 also indicates that, in the G5S and G10LS classes, the most frequently occurring sub-codes were "fact" $(29.10 \%)$ and "opinion" $(20.6 \%)$, respectively. This suggests science students tended to consider brief facts (e.g., domain-specific vocabularies and concepts) 
01

02

03

05

\section{Ex} the rapid expansion of surrounding gas becomes mechanical power. It is accompanied by a strong exothermic, light and sound effect. The rapid chemical reaction in a certain environment will cause dramatic expansion of gas. The wall of the environment can be damaged or even ruptured by the explosion. Explosion can also damage the nearby objects and organisms. Moreover, chemical reactions caused by a crash of astronomical objects and lightning can be also called explosion. center of the solar system. $99.87 \%$ of the solar system energy resides in the sun. The eight planets in the solar system, asteroids, meteors, comets, and interstellar dust are revolution around the sun. objects in the space. Its broader meaning include everything in the universe. Website

http://hk.knowledge.yahoo.com/question/question?gid= 7007100403347
D. KS_Fact-oriented discourse

20: 10 : Explanation-seeking

Information Stated

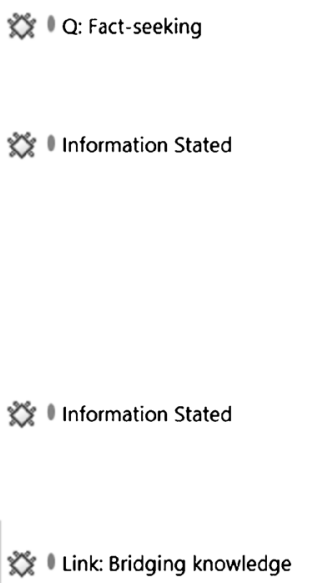

Fig. 5 Example of a narrative unit

as self-explanatory, while humanities students tended to use subjective judgments when explaining social issues. "Social-affective-communal" was the second most frequent main code, with $20.9 \%$ of the total discourse. However, its frequency varied substantially across classes, accounting for only $6.21 \%$ of G5S class discourse, but $35.7 \%$ of G10VA class discourse, suggesting the latter class dedicated considerable efforts to creating a positive social climate and treating each other as real persons in KF. "Question" was the third most frequent dimension, with $16.5 \%$ of total discourse.

"Agency" made up $7.59 \%$ of the total discourse, with most instances being found in the "metacognitive knowing evaluation" sub-code (4.40\%), suggesting students were more aware of the validity of one another's ideas than other aspects of "agency." "Information," "linking," and "meta-discourse" were the least frequently occurring main codes, and together comprised less than $10 \%$ of total discourse. This result was similar to those of van Aalst (2009). Although "agency," "information," "linking," and "meta-discourse" are theoretically important dimensions of discourse, they appeared infrequently in the data set in spite of the development of sub-codes to operationalize these dimensions. 
Table 3 Summary of the frequency of the main code and sub-codes

\begin{tabular}{|c|c|c|c|c|c|c|c|c|}
\hline & \multicolumn{2}{|c|}{ Grade 5 science } & \multicolumn{2}{|c|}{ Grade 10 visual art } & \multicolumn{2}{|c|}{ Grade 10 liberal studies } & \multicolumn{2}{|c|}{ Total } \\
\hline & No. & $\%$ & No. & $\%$ & No. & $\%$ & No. & $\%$ \\
\hline Social-Affective-communal & 22 & 6.21 & 141 & 35.70 & 27 & 16.9 & 190 & 20.90 \\
\hline Agreement & 16 & 4.52 & 39 & 9.87 & 20 & 12.5 & 75 & 8.25 \\
\hline Compliment & 0 & 0.00 & 2 & 0.51 & 1 & 0.63 & 3 & 0.33 \\
\hline Different views & 2 & 0.56 & 9 & 2.28 & 6 & 3.75 & 17 & 1.87 \\
\hline Disclose personal issues & 0 & 0.00 & 6 & 1.52 & 0 & 0.00 & 6 & 0.66 \\
\hline Disclose vulnerability & 0 & 0.00 & 6 & 1.52 & 0 & 0.00 & 6 & 0.66 \\
\hline Emotions & 0 & 0.00 & 34 & 8.61 & 0 & 0.00 & 34 & 3.74 \\
\hline Humor & 4 & 1.13 & 18 & 4.56 & 0 & 0.00 & 22 & 2.42 \\
\hline Salutation & 0 & 0.00 & 16 & 4.05 & 0 & 0.00 & 16 & 1.76 \\
\hline Seeking views & 0 & 0.00 & 3 & 0.76 & 0 & 0.00 & 3 & 0.33 \\
\hline Shared experience & 0 & 0.00 & 6 & 1.52 & 0 & 0.00 & 6 & 0.66 \\
\hline Team spirit & 0 & 0.00 & 2 & 0.51 & 0 & 0.00 & 2 & 0.22 \\
\hline Information & 29 & 8.19 & 13 & 3.29 & 3 & 1.88 & 45 & 4.95 \\
\hline Information stated & 0 & 0.00 & 0 & 0.00 & 2 & 1.25 & 2 & 0.22 \\
\hline Information introduced & 26 & 7.34 & 1 & 0.25 & 0 & 0.00 & 27 & 2.97 \\
\hline Information source & 0 & 0.00 & 1 & 0.25 & 0 & 0.00 & 1 & 0.11 \\
\hline Information interpreted & 3 & 0.85 & 11 & 2.78 & 1 & 0.63 & 15 & 1.65 \\
\hline Question & 84 & 23.73 & 54 & 13.67 & 12 & 7.50 & 150 & 16.50 \\
\hline Fact seeking & 17 & 4.80 & 6 & 1.52 & 1 & 0.63 & 24 & 2.64 \\
\hline Clarification & 0 & 0.00 & 12 & 3.04 & 0 & 0.00 & 12 & 1.32 \\
\hline Explanation seeking & 18 & 5.08 & 13 & 3.29 & 2 & 1.25 & 33 & 3.63 \\
\hline Sustained & 49 & 13.84 & 23 & 5.82 & 9 & 5.63 & 81 & 8.91 \\
\hline Idea & 191 & 53.95 & 132 & 33.42 & 94 & 58.7 & 417 & 45.87 \\
\hline Fact & 103 & 29.10 & 24 & 6.08 & 8 & 5.00 & 135 & 14.85 \\
\hline Opinion & 21 & 5.93 & 23 & 5.82 & 33 & 20.6 & 77 & 8.47 \\
\hline Analogy & 4 & 1.13 & 2 & 0.51 & 2 & 1.25 & 8 & 0.88 \\
\hline Conjecture & 13 & 3.67 & 61 & 15.44 & 42 & 26.3 & 116 & 12.76 \\
\hline Elaboration & 37 & 10.45 & 0 & 0.00 & 0 & 0.00 & 37 & 4.07 \\
\hline Explanation & 13 & 3.67 & 20 & 5.06 & 9 & 5.63 & 42 & 4.62 \\
\hline Summary/synthesis & 0 & 0.00 & 2 & 0.51 & 0 & 0.00 & 2 & 0.22 \\
\hline Linking & 7 & 1.98 & 17 & 4.30 & 4 & 2.50 & 28 & 3.08 \\
\hline Bridging knowledge & 1 & 0.28 & 7 & 1.77 & 0 & 0.00 & 8 & 0.88 \\
\hline Referencing & 6 & 1.69 & 10 & 2.53 & 4 & 2.50 & 20 & 2.20 \\
\hline Agency & 20 & 5.65 & 31 & 7.85 & 18 & 11.3 & 69 & 7.59 \\
\hline Metacognitive knowing & 5 & 1.41 & 4 & 1.01 & 1 & 0.63 & 10 & 1.10 \\
\hline Metacognition knowing evaluation & 12 & 3.39 & 13 & 3.29 & 15 & 9.38 & 40 & 4.40 \\
\hline Metastrategic knowing & 1 & 0.28 & 5 & 1.27 & 2 & 1.25 & 8 & 0.88 \\
\hline Metastrategic knowing evaluation & 1 & 0.28 & 5 & 1.27 & 0 & 0.00 & 6 & 0.66 \\
\hline Shared regulation & 1 & 0.28 & 4 & 1.02 & 0 & 0.00 & 5 & 0.55 \\
\hline Community: Meta-discourse & 1 & 0.28 & 7 & 1.77 & 2 & 1.25 & 10 & 1.10 \\
\hline Lending community support & 0 & 0.00 & 1 & 0.25 & 0 & 0.00 & 1 & 0.11 \\
\hline Problem synthesis \& analysis & 1 & 0.28 & 3 & 0.76 & 2 & 1.25 & 6 & 0.66 \\
\hline Problem transfer & 0 & 0.00 & 3 & 0.76 & 0 & 0.00 & 3 & 0.33 \\
\hline
\end{tabular}

The codes' definitions are presented in Table 2 


\section{Narrative analysis}

We identified 69 units of analysis and identified 9 distinct discourse patterns. Table 4 lists and defines the patterns, and reports their frequencies in each of the three discussion views. Knowledge-sharing discourse was the most common, occurring 46 times. Knowledge-construction discourse occurred 12 times, and knowledge-building discourse five, indicating that knowledge sharing was pervasive in $\mathrm{KF}$ discussions, while knowledge building was comparatively rare.

The G5S view had 25 narrative units, including 22 knowledge-sharing units and three knowledge-construction units. Students mostly engaged in fact-oriented, repetitive, and cumulative discourse, suggesting they tended to accumulate factual knowledge, and might not have known how to engage in conversational exchanges in online environments.

The G10VA view had 34 narrative units, including 18 knowledge-sharing units, seven knowledge-construction units, and three knowledge-building units. This was the only class to engage in social (chitchat) discourse (six occurrences) - seemingly off-task conversations in which students teased each other, introduced themselves, or recalled shared experiences. While some researchers believe chitchat does not contribute to student learning and thinking (e.g.,

Table 4 Nine discourse patterns within three modes of discourse

\begin{tabular}{|c|c|c|c|c|c|}
\hline Discourse and pattern & Features & G5S & G10VA & G10LS & Total \\
\hline Knowledge sharing & $\begin{array}{l}\text { Question-and-answer exchanges focusing on } \\
\text { sharing information and personal ideas }\end{array}$ & & & & 46 \\
\hline - Fact-oriented & $\begin{array}{l}\text { Asking fact-oriented questions and sharing factual } \\
\text { information }\end{array}$ & 9 & - & - & 9 \\
\hline - Cumulative & $\begin{array}{l}\text { Focusing on confirmation and repetition, and } \\
\text { conflicting ideas being ignored and assimilated }\end{array}$ & 5 & 5 & 2 & 12 \\
\hline - Repetitive & $\begin{array}{l}\text { Merely responding to a seed note or question and } \\
\text { lack of interactions }\end{array}$ & 8 & 7 & 1 & 16 \\
\hline - Simple argumentation & $\begin{array}{l}\text { Defending own position, and rebuttal is eitherabsent } \\
\text { or blocked out }\end{array}$ & - & - & 2 & 2 \\
\hline - Disputational & $\begin{array}{l}\text { Finding out "who's right and who's wrong" and } \\
\text { "what's wrong with your idea" }\end{array}$ & - & 6 & 1 & 7 \\
\hline Knowledge construction & $\begin{array}{l}\text { Ideas are elaborated, explained and inquired into } \\
\text { working towards construction of knowledge and } \\
\text { understanding }\end{array}$ & & & & 12 \\
\hline $\begin{array}{l}\text { Explanatory \& } \\
\text { problem-centered } \\
\text { inquiry }\end{array}$ & $\begin{array}{l}\text { Posing problems; elaborated explanation, and } \\
\text { viewing ideas as problematic that need further } \\
\text { inquiry }\end{array}$ & 3 & 7 & 1 & 11 \\
\hline - Complex argumentation & $\begin{array}{l}\text { Constructing understanding through argumentation } \\
\text { that bring ideas to higher levels }\end{array}$ & - & - & 1 & 1 \\
\hline Knowledge building & $\begin{array}{l}\text { Community knowledge advancement through } \\
\text { sustained inquiry }\end{array}$ & & & & 5 \\
\hline - Progressive inquiry & $\begin{array}{l}\text { Engaging in deepening explanation and emerging } \\
\text { questions for continual idea improvement; } \\
\text { problem analysis and transfer }\end{array}$ & - & 1 & 1 & 2 \\
\hline $\begin{array}{l}\text { - Sustained discourse for } \\
\text { community advance }\end{array}$ & $\begin{array}{l}\text { Contributing to high-level ideas and problems to } \\
\text { advance problems of community interest; } \\
\text { lending support to community advances; } \\
\text { persisting in producing knowledge that is } \\
\text { relevant to the community members }\end{array}$ & - & 2 & 1 & 3 \\
\hline
\end{tabular}


Weinberger and Fischer 2006) or pertain to the three modes of discourse, chitchat patterns are noteworthy as they may also reflect the warm classroom climate and relationships in this classroom community.

The G10LS view had 10 narrative units, including six knowledge-sharing units, two knowledge-construction units, and two knowledge-building units. Table 4 suggests that only the G10LS students had simple argumentation, complex argumentation, and theory-oriented interactions, perhaps due to the nature of the subject, which is similar to Social Studies. According to the curriculum, Liberal Studies encourages students to generate multiple perspectives on a contemporary social issue through the use of argumentation (Curriculum Development Council 2007).

The following subsections describe and explain each pattern. The original discourse excerpts were in Chinese and translated by the first author. An ellipsis (“...") indicates the omission of long messages. We replaced all of the students' names with class names and numbers to preserve anonymity. For example, "5A19" refers to a student from the highest-ranking form 5 (Grade 11) class, and "4E28" to a student from an academically weaker form 4 (Grade 10) class (that is, the fifth class in that grade).

\section{Knowledge-sharing discourse}

Knowledge-sharing discourse consisted of question-and-answer exchanges that focused on sharing information and personal opinions, not formulating and addressing a problem. During their online discussions, students' ideas were not developed and improved, and there was limited uptake of previous ideas that had been ignored or responded to superficially; new notes only added information and restated views. Five knowledge-sharing discourse patterns were identified: fact-oriented, cumulative, repetitive, simple argumentation, and disputational discourse.

\section{Fact-oriented discourse}

Fact-oriented discourse is characterized by factual information and fact-seeking questions (Hakkarainen 2003b). Fact-seeking questions (i.e., those asking who, where, when, how many and (sometimes) what) can be addressed by factual information (Hakkarainen 2003a). For example, when one student asked, "What is voltage?" another copied a factual definition of voltage from the Internet. Some fact-oriented discourse patterns began with explanation-seeking questions, but were addressed by factual information only:

5A19 Why does contact between fire and electricity trigger an explosion?

5A23 Explosion means ... [factual information copied]. Moreover, a chemical reaction caused by a crash of astronomical objects and lightning can be also called an explosion.

$5 \mathrm{~A} 01$ What is an astronomical object?

$5 \mathrm{~A} 30$ The sun is the most nearby fixed star of the earth ... [factual information copied].

5A21 Astronomical object is also known as starts ... [factual information copied and a website].

5A19's question was only partially addressed by 5A23's factual information response, the content of which was beyond the comprehension of Grade 5 students. 
Therefore, 5A01 ignored the gist of the information (and 5A19's explanation-seeking question) and asked for the definition of the single term, "astronomical object." Chan (2001) called this kind of response a surface-centered discourse move, one which ignores, rejects, or eliminates the differences between peers' ideas to minimize the effort required to revise their current understanding. 5A10's discourse move turned the explanation-seeking question into a fact-seeking question, causing significant discussion topic drift, with $5 \mathrm{~A} 30$ and $5 \mathrm{~A} 21$ then focusing on sharing factual information about astronomical objects. Table 4 shows that fact-oriented discourse was found only in the G5S view, suggesting Grade 5 students often used surface-centered discourse; rather than making an effort to interpret information shared by their peers, they simply focused on a single aspect thereof.

\section{Cumulative discourse}

Cumulative talk in face-to-face classroom discourse is characterized by repetition and confirmation (Mercer 1996). As shown in Table 4, this pattern also frequently occurred in the online discussion forums, with students not critically examining and challenging one another's ideas during their interactions.

5A29 Why do conductors allow the flow of electric charge?

5A37 Copper, iron, silver, etc. are good electrical conductors.

5A07 All good electrical conductors are metal.

5A33 Of course not! Apart from metal, iron is also a good electrical conductor.

5 A35 Iron is also a kind of metal. For example, iron, gold, copper, silver, and water are good electricity conductors.

5A29's "why" question was distorted into a "what" question when 5A37's surface-centered discourse move responded to it as if it were another question whose answer was already known. Although in the last message 5A35 clarified 5A33's response ("Iron is also a kind of metal"), the clarification did not influence the subsequent interaction. As the following indicates, students could comfortably participate in the discussion - without inquiry - by listing examples of electrical conductors.

5A10 Aluminum too!

$5 \mathrm{~A} 08$ Water is too!

5A02 Water contains metal objects.

5A10 Also mineral.

\section{Repetitive discourse}

In repetitive discourse, students shared their perspectives on the first note in a cluster without engaging in genuine discussion, sometimes even repeating what others had said without awareness of what had already taken place in the discourse. The Knowledge Building Teacher Network teachers called this a "star-shaped" pattern, reflecting the recognizable physical shape of such note clusters. We found three physical variations in repetitive discourse pattern (see Fig. 6).

Figure 6's left-hand panel shows the simplest example, with five second-level notes build on to the same seed note. These responses are generally independent-i.e., referring to the seed 


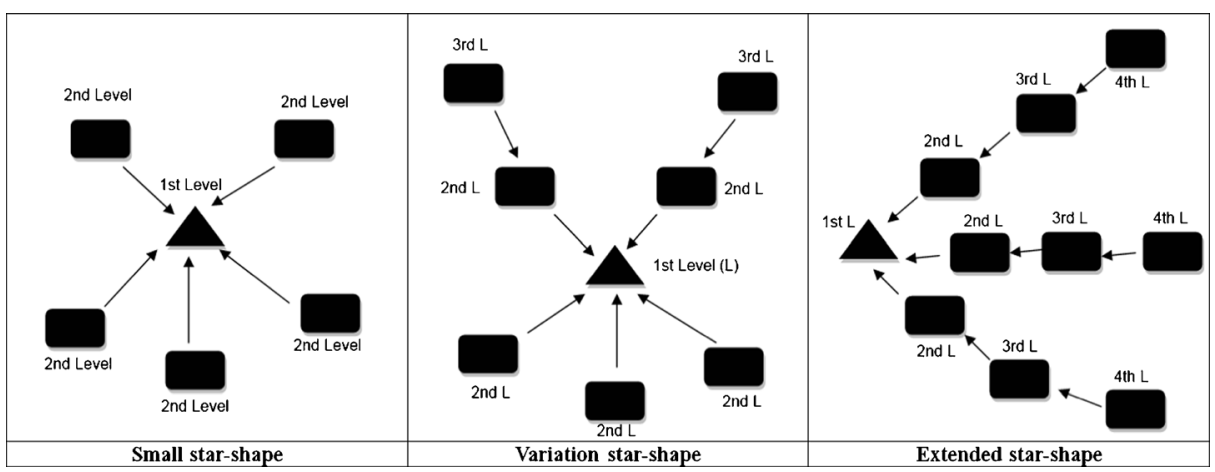

Fig. 6 Three variations of repetitive discourse

note, but making no response to any other second-level notes. For example, 5A23 asked, "Why is water a type of electronic conductor?" and received six independent replies.

5A21 Water itself is not an electronic conductor; its metallic minerals are.

5A06 Anything can be an electronic conductor as long as the voltage is high. Pure water is not electrically conductive given that it is at a certain level of voltage.

5A26 Drinkable water is an electronic conductor because it contains metallic minerals.

5A28 Drinkable water itself is not an electronic conductor, but it has metallic minerals.

5A19 Electricity can flow along with water flow.

$5 \mathrm{~A} 03$ Because water is a conductor.

Three responses (5A21, 5A26, and 5A28) introduced the concept of metallic minerals, one (5A06) mentioned the relationship between conductors and voltage, and one (5A19) introduced the concept of water flow; however, as the students focused on the initial question, these concepts were not developed further. Repetitive discourse allows students to share their diversity of ideas. The variation in Fig. 6's center panel shows third-level responses to second-level notes, and the extended star shape in the right panel shows several parallel threads build upon the seed note; however, these threads are too short to bring about knowledge construction or knowledge building. Repetitive discourse occurs frequently when a teacher posts a key question and most students respond to the question.

In summary, although note clusters showing repetitive discourse patterns may comprise numerous notes, they do not include interactions between students. Since a unit of narrative includes at least five connected notes in this study, when the parallel threads of an extended repetitive pattern comprised more than fourth-level notes, they were analyzed as another unit of narrative, as shown in Fig. 3.

\section{Simple argumentation}

Simple argumentation reflects a clear opposition between students (Erduran et al. 2004), with a focus on selecting and defending a position. Students merely chose a position and expressed their argument.

4E16 A lot of Hong Kong people use a "confrontational" approach to express their dissatisfaction with the government, such as demonstrations and protests. ... Why don't 
we use a "dialogical" approach? We need to have conversation to solve problems. Problems cannot be solved by violence.

4E28 I do not agree. The reason why people use the confrontational approach is that the dialogical approach does not work. If the government listened to public opinions, people would not use the confrontational approach.

4E08 I do not agree. The government may not make compromises, even if people resorted to violence. We should use the dialogical approach to solve problems.

4E28 Violence may not solve all problems. But if soft approaches cannot get the government's attention, we can only resort to radical approaches.

4E16 If we do not use the "dialogical" approach to resolve differences, the "confrontational" situation will last. In the long term, this will produce a negative social climate.

After 4E16 introduced the confrontational and dialogical communication approaches, other students focused on supporting one of the approaches without addressing the arguments of others. Rebuttals or evidence were not found and students just argued on the basis of their opinion. Erduran et al. (2004) proposed that the quality of argumentation can be assessed by the strength of the rebuttals found in a series of related utterances and that rebuttals provide an opportunity for the opposition to revise its original claim. However, in this pattern, although rebuttals occurred even in simple argumentation, they were not taken up.

\section{Disputational discourse}

Disputational talk is well known in face-to-face classroom discourse; it is characterized by disagreement and unconstructive responses (Mercer 1996). In this study, students who engaged in disputational discourse focused on determining "who's right/wrong" and pointing out "what's wrong with your idea"; they emphasized the flaws in others' ideas without helping them to develop the valuable aspects thereof. The conversations tended to be uncooperative, and the online discussions terminated prematurely.

$4 \mathrm{C} 12$... what kinds of artwork can be regarded as "reflecting a community's characteristics"?

4A11 You succeed if others can immediately recognize which community you are working on!!

4C02 Objection!! Does it mean that you fail if others cannot immediately recognize which community you are working on? It may not be the case.

4E26 Yes! Every artist has a personal style! For example ...

4A11 Okay! I am wrong.

4C02 If we do things very well all the time, we don't have a chance to make improvements ...

4A11's opinion came under attack. Although 4A11 acknowledged the problem (“Okay! I am wrong"), 4C02 further explained what was wrong with 4A11's opinion. 4C12's original question was abandoned, and the remainder of the conversation focused on what was wrong with 4A11.

Most of the knowledge-sharing discourse patterns identified herein are familiar from studies of classroom discourse (e.g., Mercer 1996), but point to a variety of reasons why online discourse can fail to become constructive. Questions requiring factual answers are important for building knowledge, but facts are often not questioned, so the fact-oriented discourse is short; this may reflect such simplistic knowledge beliefs as quick learning, certain knowledge, 
or an absolutist perspective (King and Kitchener 1994; Kuhn 2005; Schommer 1990). Repetitive discourse does not involve interaction. In this case, it might have arisen from students' understanding of what needed to be done (e.g., everyone had to answer the teacher's question), or their not knowing how to sustain a discussion's focus. Simple argumentation focuses on persuading an opponent rather than improving an idea, and therefore differs from knowledge-building discourse (Scardamalia and Bereiter 2006); however, it also falls substantially short of what proponents of "arguing to learn" see as the value of argumentation (Andriessen 2006). Disputational discourse is not usually sustained because ideas are considered personal property, not shared, improvable objects (as in knowledge building). In this study, cumulative discourse appeared because students seemed ignorant of how to engage in more constructive discourse.

\section{Knowledge-construction discourse}

Knowledge-construction discourse refers to the development of constructive understanding by means of elaboration, explanation, and problem solving (van Aalst 2009). In this study, students often elaborated on the discourse and built on another's ideas using examples, arguments, and evidence. They engaged in problem solving driven by the generation of questions, which often began with an explanation-seeking question followed by clarification and sustained questions. Students also generated multiple ideas and shared relevant pieces of information. They examined the validity of ideas, asked questions and pressed for further inquiry, and made constructive comments. We identified two discourse patterns: explanatory and problem-centered inquiry, and complex argumentation.

\section{Explanatory and problem-centered inquiry}

This kind of discourse pattern is characterized by problem recognition and explanation construction. In this study, students displayed a careful uptake of previous responses (Suthers and Medina 2011), viewing ideas as problematic and in need of inquiry and explanation (Chan 2001). Instead of just posing unrelated information or asking for information, they engaged in explanatory inquiry, asked questions to elicit elaborative explanations from their peers, recognized the thrust of previous ideas, and identified gaps in knowledge:

5A29 Why do conductors allow the flow of electric charge?

5A37 Copper, iron, and silver are good electricity conductors.

5A03 What are good electrical conductors? Are there any bad electrical conductors?

5A35 Poor electrical conductors are known as insulators. They are objects that electricity cannot pass through easily...

5A10 Air is also an insulator.

5A20 Supplement. An insulator is a substance that can prevent heat and electrical current...

$5 \mathrm{~A} 37$ So what is the mechanism?

$5 \mathrm{~A} 20$ There is a big distance between the valence band and conducting band in insulators...

5A29 posed an explanation seeking question and interestingly 5A37 responded though not providing an explanation but just listing the good conductors. However, this discourse did not degenerate into a fact-based discourse; there was careful uptake of information and others pursued 
the inquiry and recognized areas that need to be explained. 5A03 recognized that the modifier "good" was puzzling and required elaboration, and so formulated a question that led to an inquiry about another concept (insulators), to which 5A35, 5A10, and 5A20 contributed different explanatory ideas. 5A37 identified a deeper-level problem, and asked, "So what is the mechanism?" The problem allowed 5A20 to develop another explanation in the final message. Domain-specific terms (insulator) were not viewed as explanations in themselves, but as the starting point for building explanations. Another example taken from the G10VA class shows this:

4A28 How can community art be used to preserve heritage?

4D11 Community art can be used to magnify the information, so more people can get to know the history of a community.

4A28 How can it be used to magnify?

4D07 We create a piece of artwork to tell people why a particular community must be preserved.

4E11 Yes. For example, we recently created a piece of artwork in school. Our goal was to disseminate the importance of community conservation and heritage preservation.

4D16 I agree. Our artwork not only publicized the importance of community conservation, but also illustrated the characteristics of the target community. The three Chinese letters represented ...

4E11 I agree that our artwork illustrated the characteristics of that community. But how did our artwork publicize the importance of community conservation? Did it relate to some sort of meaning on a deeper level?

4A28 did not understand 4D11's explanation and so asked for further explanation ("How can it be used to magnify?"). 4E11 used their recent artwork to build on 4D07's explanation, and 4D16 further developed the example by providing artwork details. These students engaged in a problem-centered discourse move to consider their peers' ideas and then made contributions to improve them. 4E11 not only asked for further question but proposed some ideas to address the question. In problem-centered discourse, students identified problems and pursued explanation.

Both examples show how the students acknowledged one another's ideas and identified the aspects they needed to know more about in order to address the problem.

\section{Complex argumentation}

Similar to simple argumentation, complex argumentation involves clear opposition between students (Erduran et al. 2004). However, students who used complex argumentation patterns built upon others' statements to develop a coherent, opposing position. Students offered clearly identifiable rebuttals, which were taken up by others and elaborated to further their own arguments. In complex argumentation, students do not just share their opinion but also refer to evidence to support their arguments. The following example includes two positions (antigovernment and pro-government) and attempts to tackle/integrate others' viewpoints:

4A06 Radical behavior in the society is getting more and more serious because the fundamental social conflict is growing. What are the underlying factors?

In the first note, 4A06 asked a question about the factors causing social conflicts in Hong Kong. In the following, 4A14, 4A07, and 4A25 held an anti-government position, arguing that government's policy was perfunctory. 
$4 \mathrm{~A} 14 \ldots$ the factors are incubated for a long time. The public cannot tolerate the government's policy which leads them to take violent action ... For example, the government said that it is difficult to have fine-tuning in the financial budget. But as there is a growing anger shown by the public, the government withdrew the previous remark and planned to distribute HK\$6000 to Hong Kong permanent residents aged over 18 years old ... it shows the perfunctory attitude of the government in performing the duty ...

4A07 ...the government should reflect the underlying factors for causing social conflicts. The government only undertook superficial policies perfunctorily to regain people's support. However, the fundamental social problems still cannot be solved... According to the financial budget, although every Hong Kong citizens aged 18 years old can get HK $\$ 6000$, this cannot solve the issue related to the extreme disparity between the rich and the poor...

4A25 There is communication gap between the government and the public and the government is lack of transparency in policy making ... For example, the public continuously expressed a request for minimum wage for 5 years ... Distributing HK\$6000 to Hong Kong people is just a mean to prevent the event from exacerbating ...

First, 4A14 referred to a scheme (“distributing HK\$6000") as an evidence and claimed that the scheme was introduced by the government only after a growing anger in the society. 4A07 and 4A25 built upon what 4A14 said and suggested that the scheme could not solve such social problems as the gap between rich and poor and the lack of minimum wage. In the following, students took the other position but the arguments built on to what had already been discussed, including elaboration and explanation.

$4 \mathrm{E} 01 \ldots$ The radical behavior will only make the government respond to people's need promptly. This in turns inspires the government to deal with the social problems perfunctorily ... Distributing HK $\$ 6000$ is a good example. The government wanted to satisfying the people's need and demotivating them using radical means to express their opinion. People should make a concession to leave more space for government officials to solve the problem devotionally.

4E05 The government is not unwilling to solve the fundamental social conflicts. The government cannot solve all social problems in one step... it takes time ... For example, the government launched a housing scheme that would help people who lack initial deposit money buy a flat. The scheme was organized by ...

4A02I agree with what you said ... the government launched the housing scheme in view of the high housing prices ... However, this scheme is criticized in every aspect ... An onion can serve as an analogy for describing our social problems ...the government is trying to unleash the skin of onion step by step, eventually the core problem can be solved, but it takes time.

4E01, 4E05, and 4A02 took a pro-government position, claiming that the government was trying to solve social problems. 4E01 rebutted the anti-government claim by interpreting the same evidence ("distributing HK\$6000") from another perspective. 4E05 and 4A02 strengthened the rebuttal by using another example ("the housing scheme") and emphasized that solving social problems required time. The students seemed to engage in genuine interactions, generating multiple ideas and alternative explanations/arguments to improve their claims and rebuttals, and 
supporting their arguments with evidence. Despite their different positions, students' contributions and arguments helped their peers develop their own ideas further for knowledge construction.

Explanatory and problem-centered inquiry and complex argumentation are knowledge-construction discourse involving deepening discourse moves. In this study, surface-centered discourse moves found in knowledge-sharing discourse were used to ignore, reject, or block differences between ideas, while problem-centered and deepening discourse moves found in knowledge-construction discourse were used to carefully engage in different ideas and subject problematic ideas to further discussion. Chan (2001) found that student dyads who engaged in problem-centered discourse moves during face-to-face discussions outperformed dyads who made surface-centered discourse moves. This finding is consistent with the underlying principle of constructivism - that the process of cognitive growth is reflected in the patterns of interaction in an activity system (Greeno 2006), because interactions require students to articulate and develop explanations that facilitate cognitive growth (Schwartz 1995). Problem-centered and complex argumentation discourse patterns involving interaction, elaboration, explanatory-inquiry, and deepening illustrate productive online collaborative interactions for knowledge construction.

\section{Knowledge-building discourse}

Knowledge-building discourse has the characteristics of knowledge-construction discourse, but its key features are sustained pursuit of inquiry and community goals. Knowledge advancement is driven by sustained inquiry, which is enabled by progressive problem solving in which students continuously re-define the problem for deepening inquiry, engage in rise-above synthesis, and help the community understand the issues being discussed. This study identified two knowledge-building discourse patterns: progressive inquiry and sustained discourse for community advance. The two patterns entailed students' use of problem-centered discourse moves but were more sustained than knowledge-construction discourse, as the students demonstrated epistemic agency with community goals.

\section{Progressive inquiry}

This pattern demonstrates the initial characteristics of progressive inquiry, in which knowledge is gradually advanced in a community. Students use sustained inquiry to formulate research questions and pursue knowledge advancement through emergent questions (Hakkarainen 2003b). In this study, students chose explanations that held the most promise for further development to formulate more specific, subordinate questions, and to direct knowledge advancement (Hakkarainen and Sintonen 2002):

4A11 Does collective memory involve aesthetic value?

4E16 What does it mean by aesthetic value?

4E11 Aesthetic value refers to your feeling and experience of appreciating aesthetic objects. From the feeling of like or dislike, you obtain the perception of value.

4A28 In other words, aesthetic value is a subjective issue that is not affected by external factors 
4E11 Nope, Nope. Although aesthetic value is mainly influenced by subjective factors, it is also influenced by objective factors. As I said earlier, your judgment that bases on your knowledge and understanding of an art work involves objective factors.

4E16 asked a more specific question to clarify a key concept, aesthetic value, from the first note. 4E11 responded that the concept related to their "feeling and experience," and 4A28 built on her response and introduced another concept ("subjectivity") to explain aesthetic value. 4E11 showed a careful uptake of 4A28's idea, and revised her initial idea ("feeling and experience") to introduce the objective factors influencing their perception of aesthetic value. The discussion continued:

4E16 Your understanding and conception of an art work is equal to personal perception? 4E11 Yes, to a certain extent, one's conception of an art work is equal personal perception. However, this kind of perception is a more objective sort of judgment.

4E16 People from different backgrounds perceive an art work differently. Where does the objectivity come from? If the judgment is objective, it is just a consensus toward an art work.

4E11 I agree with your idea. Different people have different perceptions. Apparently, it is subjective thinking, but there is also another level - objectivity. Objectivity is different from subjectivity. Objectivity is from the third person perspective. It is independent and deals with facts. A principle that everybody knows and ascertains does not mean subjective thinking. For example ... Consensuses are formed by a negotiation between objectivity and subjectivity.

4E11 Objective conception and subjective judgment is good for differentiating different things. For example, let's says John's height is 1.8 meter; that is an objective statement; whether John is tall or short is a subjective statement ... All objective matters can be "measured" but they cannot be "judged"; all subjective matters can be "judged" but they cannot be "measured" ... Objectivity solves "what" and "how" kinds of questions; subjectivity solves "good or bad" and "how" kind of questions ... http://baike.baidu. com/view/176035.htm\#5

4E16 seemed to be confused by the idea of objective factors, thus raised a question to seek a better explanation. 4E11 further explained the concept of an "objective sort of judgment"; however, 4E16 was not satisfied, and formulated a specific question for direct knowledge advancement ("where does the objectivity come from?"). To address this question, 4E11 developed rise-above ideas, synthesizing earlier responses by putting objectivity and subjectivity together and conceptualizing objectivity and subjectivity with reference to online information. Questions and explanations were intertwined and iterative. With sustained inquiry, the class progressively revised and improved its understanding of aesthetic value. Epistemic agency was evidenced by the students' continuous effort to engage in earlier ideas, formulate emerging questions, and pursuit idea improvement.

\section{Sustained discourse for community advance}

Like progressive inquiry, sustained discourse for community advance also entails the formulation of further questions. Its key features are students' sustained efforts at pursuing inquiry, community awareness, regulation in advancing the discourse, and the production of knowledge useful to their community. 
4D07 Can community art facilitate community development@@?

4D16 It can. Community art may reflect public dissatisfaction with the current community. This may contribute to community development.

4D15 What does "reflecting dissatisfaction with the current community" mean?

4E16 Dissatisfaction with the problems that exist in the current community-for example, environmental and hygienic issues. The government intended to build a garbage incinerator on an island, and the island residents were worried ...so they created a banner in their community to express their concerns.

$4 \mathrm{E} 11$... Does anything dissatisfy the residents in your own community, causing them to reflect on the community development? Can you elaborate on it?

Here, 4D15 generated a specific question, requesting elaboration on a key concept in the previous idea ("reflecting dissatisfaction with the current community"). After 4E16 explained, 4E11 invited more elaboration and suggested personal experiences be applied to develop the explanation. 4E11 specifically prompted information from classmates, suggesting community awareness and efforts to help the community move further. The discussion continued:

4D16 Here is an example of dissatisfaction from my community. Regarding the construction of the high-speed rail, the residents are worried ... A thousand of them went to protest. This dissatisfaction leads us to contemplate the community development...

4E11 But can this discontent facilitate idea exchanges among communities? Are there better approaches?

4D16 ... public protest is a kind of human right about personal freedom. I personally... don't want to see this right disappear ...

4E11 I remember... a student from another school proposed that we needed to rationally deal with problems. I agree with him ... We can peacefully write down our perspectives on the Internet...

4D16 To work along both lines... Based on our knowledge, it is better to use both means, which include concrete action (demonstration) and word expression (Web)...

4E11 What I mean is...A survey shows that... According to the statistics of "Internet World Stats"... The Chief Executive said ... I think that words can be another way of letting people express their views, which in turn makes the government policies cater to people's demand.

4D16 and 4E11 applied their personal experiences and knowledge to generate and compare more ideas, and improve their explanations. They used the concept of "dissatisfaction with the current community" to explain their perspectives on community development and ways of expressing public opinion to the government. 4D16's rise-above considered different views expressed earlier and specifically noted "based on our knowledge," implying a collective stance towards knowledge as residing within the group. Furthermore, whereas 4D16's summary note ("to work along both lines") could have ended the inquiry satisfactorily, 4E11 pursued further improving the summary via multiple sources of information, suggesting she wanted to help the community gain a better understanding of how to express public opinions.

Knowledge building discourse entails not only incorporating multiple online discourse ideas in a synthesis, but also ensuring others can follow what is being discussed (Stahl 2011) for community advance; students went beyond learning textbook content and made 
constructive use of other information to explain their perspectives on social phenomena (ways of expressing public opinion). The focus on community can be considered an effort to produce knowledge, as the students were pursuing inquiry and developing concepts to explain the phenomena (Bereiter 2002a). The discussion continued as a student raised a higher-level question that address community goal:

4A13 How do all these relate to community art?

$4 \mathrm{D} 16$... These are about the options in a community. The options refer to the ways in

which we express our perspectives and expectations of the society...

4A13 was concerned that the original question about "community development" would digress into another discussion on expressing public opinions. 4D16 addressed this concern and synthesized previous ideas to explain the function of community art in a larger social context. van Aalst (2009) noted knowledge-building discourse entails a sense of community, in which students establish their social practice to work for knowledge advancement. This excerpt shows epistemic agency manifested in sustained inquiry; community awareness and regulation, which prompts others to elaborate; synthesis of multiple views being discussed; and sustained efforts to re-open the discussion to deepen inquiry and help the community understand the issues being discussed.

In summary, we identified two knowledge-building discourse patterns. In the first, progressive inquiry, students carefully considered previous ideas and, when one problem was solved, students formulated emergent and specific subordinate questions. In the second, sustained discourse for community advance, students worked to produce knowledge relevant to their classroom community. These discourse patterns involved viewing knowledge as problematic, and to be refined continually, and students' collective epistemic agency for sustaining knowledge advancement. Both patterns go beyond knowledge construction to sustained inquiry and collective efforts to move forward the frontiers of community knowledge. Damsa et al. (2010), regarding a universitylevel course, saw similar epistemic agency as enabling students to collectively create shared knowledge objects. The current study provides additional empirical illustrations for the concept of collective epistemic agency in the context of idea improvement and community knowledge in secondary school classrooms. This study also suggests that epistemic agency may enable the emergence of social practices required for knowledge building.

\section{Usability of the discourse patterns}

The discourse patterns were inferred from a specific dataset; this was a case study. An important question is whether the classification of discourse patterns is useful in the interpretation of asynchronous online discourse generated in other contexts. As suggested by Polkinghorne (1995), "the understanding of the new action can draw upon previous understanding while being open to the specific and unique elements that make the new episode different from all that have gone before" (p. 11). Although narrative analysis is not fully replicable, we expected to identify evidence of the nine discourse patterns in other datasets while remaining open to new patterns. We analyzed two other published databases from previous studies to provide reference points (Chan and Fu 2011; Niu and van Aalst 2009). We examined the nine discourse patterns developed by the narrative analysis. We identified the narrative units, examined each, and evaluated whether it shared the nine discourse patterns' characteristics.

The first dataset, also taken from the Knowledge Building Teacher Network in Hong Kong, was used to explore the change from activity-based to principle-based approaches over two 
years; we also investigated the relationships between KF engagement and domain knowledge. The other database, taken from a study conducted in Canada, was used to investigate how the discourse patterns were manifested in another research context when the teacher was starting knowledge building (Niu and van Aalst 2009).

\section{First dataset: Knowledge building in elementary school science}

The KF database selected for analysis included two cohorts (25-30 students each) of Grade 4 elementary science students with similar academic backgrounds, taught by the same teacher participating in the Knowledge Building Teacher Network (Chan 2011). Both cohorts used KF for about five months in the year; however, the teacher changed from an activity-based to a principle-based classroom design in the second year. Our analysis examined whether the discourse patterns could be identified, how they changed, and how they might relate to student domain knowledge. We conjectured that, as the teacher shifted towards principle-based understanding, there would be improved discourse and domain understanding, and therefore tested for increased frequencies in higher-level discourse patterns over time.

Our previous analysis showed improvements from a principle-based approach used over two years; the second cohort outperformed the first in terms of KF participation, including the number of notes written and read, and domain knowledge (school science tests). We also found significant relationships between KF participation and domain knowledge among students for both years, suggesting reasonable knowledge-building work (Chan and Fu 2011).

In the current study, we analyzed KF writing for discourse patterns, and investigated whether the two cohorts produced different modes of online discourse. Table 5 shows that the first cohort wrote 339 notes, and the second 663. 24 narrative units were identified in the first cohort, and 45 in the second. More than half of the narrative units were identified as knowledge-sharing discourse, including 19 of 24 units (79\%) in the first cohort, and 28 of 45 units $(62 \%)$ in the second. The second cohort produced a higher frequency of knowledgeconstruction discourse (10 of 45 units; $22.2 \%$ ) than the first cohort ( 2 of 24 units; $8.3 \%$ ). The remaining narrative units - three in the first cohort and seven in the second - showed emerging knowledge building discourse-including features of progressive problem-centered discourse.

Table 5 Summary of discourse analysis in the first- and second-year cohorts

\begin{tabular}{|c|c|c|c|c|}
\hline & First-year cohort & & Second-year cohort & \\
\hline No. of students & 40 & & 39 & \\
\hline No. of notes created & 339 & & 663 & \\
\hline No. of narrative units identified & 24 & & 45 & \\
\hline Knowledge-sharing discourse & $19(79.2 \%)$ & & $27(60 \%)$ & \\
\hline - Fact-oriented & & 3 & & 1 \\
\hline - Cumulative & & & & 1 \\
\hline - Repetitive & & 16 & & 25 \\
\hline Knowledge-construction discourse & $2(8 \%)$ & & $10(22.2 \%)$ & \\
\hline - Explanatory \& problem-centered inquiry & & 2 & & 10 \\
\hline \#Emerging Knowledge-Building & $3(12.5 \%)$ & & $7(15.5 \%)$ & \\
\hline
\end{tabular}

\#Discourse showed the initial characteristic of progressive inquiry 
Using data from published databases as reference point, we examined the validity of the discourse patterns; our findings suggest that, in parallel with changes in KF participation and domain knowledge over time, more sophisticated discourse patterns were identified as the teacher adopted a more sophisticated, principle-based practice. A detailed discussion of this analysis of is beyond the scope of this paper, but these findings suggest the presence of discourse patterns in other data sets and provide indirect evidence of the relationships among domain knowledge, KF participation, and discourse patterns.

\section{Second dataset: Canadian classrooms}

To explore whether the present study's discourse pattern classifications were applicable in other contexts, we reanalyzed a dataset from a study conducted in Canada (Niu and van Aalst 2009), in which students from two Grade 10 Social Studies classes, working in groups of approximately eight students, used KF over a three-week period to investigate aspects of the Chernobyl nuclear accident and its treatment by the media. We re-coded 230 notes from the original study's database and identified 15 narrative units, 13 of which were considered knowledge-sharing discourse: eight repetitive, four cumulative, and one disputational. Our analysis showed the discourse in this dataset to be highly fragmented with many repetitive discourses. It also showed repetitive discourses could become knowledge construction discourses if extended to involve collaborative interaction, and if students focused more on responding to ideas than on writing monologues.

Comparison of the two datasets suggested the discourse pattern classifications were reasonable. In Niu and van Aalst's (2009) study, the Canadian teacher and students were new to knowledge building, and the students worked in small groups for a short period. These factors likely contributed to only knowledge-sharing discourse being identified. Research has shown that group arrangement may be less productive than community-based discourse (Siqin et al. 2015; Zhang et al. 2009), and may contribute to a lack of sophisticated patterns. In Chan and Fu's (2011) study, the teacher conducted knowledge building for five months in year one, and for five months with another cohort in year 2; also, the teacher network supported professional development by changing from activity- to principle-based classroom design. The comparison and analysis suggest that teacher experience and classroom design were meaningfully related to discourse pattern quality. The reanalysis of the two datasets suggested the discourse pattern categories could be identified and used in different contexts.

\section{Discussion}

This is one of the few studies in knowledge building that has been entirely dedicated to identifying and characterizing different types of online discourse patterns with the involvement of teachers. It has used a combination of qualitative coding and narrative analysis to deepen understanding of nine discourse patterns found in classrooms of teachers with different knowledge-building experiences. Further, it has developed the framework of three modes of discourse proposed by van Aalst (2009) to distinguish between knowledge sharing, knowledge construction, and knowledge building. The discourse patterns identified in this study were conceptually grounded in knowledge building and provide empirical support for the three modes of discourse. Its findings provide theoretical clarification, shed light on the developmental trajectory of knowledge-building discourse, and are relevant not only for knowledge building, but also for CSCL and online forums. 


\section{Theoretical implications}

Studies have found knowledge-sharing discourse, which entails the sharing of personal opinions and fragmented knowledge (van Aalst 2009), to be a common online practice (Stahl et al. 2006; Wise et al. 2014). Knowledge-sharing discourse occurred most frequently in the current study, which is consistent with previous studies. Knowledge-sharing discourse appeared in five patterns (fact-oriented, repetitive, simple argumentation, disputational, and cumulative), which fail to sustain a line of productive inquiry. Nevertheless, knowledge-sharing discourse has its advantages, including that it seems easier to achieve than other modes of discourse, and may be an easier way to engage students in starting an online discussion.

Knowledge construction, involves students' collaborative interaction and construction of a deeper understanding of the topic or issue through elaboration, arguments, questionasking, use of information, and explanations. Through productive collaboration, students deepen their existing understanding. This mode of discourse is often examined in small groups although sometimes in large classes. This study, continuing with earlier research (van Aalst 2009) conceptualizes knowledge building discourse; herein taken as synonymous with knowledge creation, which is the main purpose of knowledge-creating organizations. Education is dominated by the concept of learning, and knowledge building is difficult to distinguish from knowledge construction (Scardamalia and Bereiter 2010; Scardamalia and Bereiter 2014). This study contributed to the empirical distinction by developing discourse patterns that clarified the characteristics of knowledge-construction and knowledge-building discourses. Both discourse types require students to detect problems in previous ideas and subject them to further inquiry (Chan 2001), a practice similar to "problematizing moves" (Koschmann et al. 2005), "exploratory talk" (Mercer 1996), and "joint problem space" (Roschelle and Teasley 1994). Students who adopt this practice may be considered successful in collaborative learning and problem solving.

The empirical illustrations of knowledge-building discourse and of their turn-by-turn interactions help to clarify the knowledge creation processes of secondary school students. Knowledgebuilding (creation) discourse focus on sustained pursuit of inquiry for creation of ideas through progressive problem solving. When one question is tackled or solved, students would raise other problems and issues for collective idea improvement. As the excerpts show, students asked emerging questions, revised earlier understanding (theories), made rise-above ideas synthesizing earlier understanding, and monitored collective understanding through new questions. In knowledge-building discourse, students are focused on community goals: they engage in discourse moves that ensure others can follow what is being discussed (Stahl 2011), and they use meta-discourse to synthesize what has been discussed and link the discourse to higher level goals.

Primarily epistemic agency is important for moving discourse from knowledge construction to knowledge building; with epistemic agency, students can continuously identify what they need to know, and can sustain their collective effort to create knowledge that is new to their classroom community. However, many teachers conceive of epistemic agency as inflexible, because they are not convinced students have the potential to create new knowledge (Hong et al. 2011; Hong and Sullivan 2009). In this study, the G10VA class had the highest frequency of "social-affective-communal" discourse, and had more knowledge-building discourse than the other classes. This finding provides some evidence that a positive socio-emotional climate is crucial for students to engage in sustained collaboration, and to take the risks necessary to show their critical comments and ignorance (Phielix et al. 2010; Rourke et al. 1999; Wegerif 1998) supported with community ethos and goals. Future research may examine the 
relationship between a positive socio-emotional climate and student epistemic agency, and how both can develop social practices that facilitate innovation and creative ideas.

There has been a great deal of research interest in the CSCL community on argumentation (Scheuer et al. 2010; Stahl 2007) and its relationship to knowledge building (Lai 2009; Leitao 2000; Mu et al. 2012; Stegman et al. 2007). This study's findings may shed light on this issue and the conceptual contrasts between knowledge building and argumentation. Bereiter and Scardamalia argued that knowledge building requires a different mode of discourse than argumentation. Rather than attempting to convince an opponent of one's beliefs, one aims to improve knowledge objects (Bereiter and Scardamalia 2003; Scardamalia and Bereiter 2006). Simple argumentation describes untutored arguments ("I disagree") and a lack of reasoned rebuttals, and focuses on defending a position one believes is true. This pattern is classified as knowledge-sharing discourse because it is not reflective and is related to naïve realism (van Aalst 2009). Complex argumentation, on the other hand, includes clearly identifiable rebuttals that opponents can use as building blocks to further elaborate their arguments. In its best form, complex argumentation has a formal argument structure (Kuhn 2005) and involves the co-construction of knowledge through which both proponent and opponent come to a better understanding of, and even improve somewhat upon, the positions being argued. The co-construction of arguments by students indicates a collaborative meaning-making process (Erduran et al. 2004); therefore, it is classified as a form of knowledge-construction discourse.

Knowledge building, however, has a very different goal. In theory, knowledge-building discourse is critical, in the sense that it tests a proposed theory and questions its assumptions, but this is done to improve the theory and not to defeat it. Some proponents of 'arguing to learn' claim the kind of argumentation they have in mind is not oppositional: "Argumentation in science is not oppositional or aggressive; it is a form of collaborative discussion in which both parties are working to resolve an issue, and in which both scientists expect to find agreement by the end of the argument" (Andriessen 2006, p. 443). However, this sounds more like complex argumentation than knowledge building, because it involves a movement from disagreement to agreement, while that goal of knowledge building is to improve knowledge objects, not change minds (Bereiter 2002b). Complex argumentation and knowledge building are both important, and students should be supported in developing competence in both.

\section{Pedagogical implications}

The findings of this study have pedagogical implications for professional development in the fields of CSCL and online learning. Both coding and narrative analysis are efforts to provide instructional guidance by shedding light on how students' online discourse can be improved. Drawing on van Aalst's (2009) coding scheme, we further conceptually developed seven discourse dimensions and 38 sub-codes applicable to different subjects and grade levels. Detailed descriptions of student discourse are especially important when studying the enactment of CSCL innovations because they inform researchers of what students are doing and not doing in online discussion forums, and how theoretical constructs manifest in their discourse. For example, although "information," "linking," and "meta-discourse" did not occur often in this study, they are nonetheless important discourse dimensions, according to theories. By using sub-codes to highlight these dimensions of student discourse, we can demonstrate to teachers what students are capable of. Using such sub-codes also allows 
researchers to work with teachers to design pedagogical supports which develop students' awareness of epistemological views of knowledge ("information"), use KF affordances ("linking"), and analyze current discourse for knowledge advancement ("meta-discourse").

The classification of discourse patterns may aid teachers in creating an epistemological shift that could facilitate the cultivation of a social practice in which student work is valued not only for performance but also its contribution to their classroom community. It has been noted that teachers' epistemological change is crucial for the enactment of classroom innovations (Chan 2011; Hong and Sullivan 2009; Scardamalia and Bereiter 2006; Zhang 2010). During our meetings with teachers in the Knowledge Building Teacher Network, we observed they focused on encouraging students to ask explanation-seeking questions; however, consistent with other studies (Palmer et al. 2008; Peters and Hewitt 2010; Wise et al. 2014), we found students' questions were often not taken up or responded to by other students. With discussion of the discourse scheme, teachers became more interested not only in individual notes but also in collective student work in clusters of notes with different discourse patterns. For CSCL, moving teachers' focus from the content of individual messages (asking more questions) to the interactions between messages is important. Teachers should encourage students to take up and work with one another's ideas. The classification of discourse patterns was developed from a chain of messages in chronological order, and showed the characteristics of productive inquiry beyond a single message.

We propose that teachers can also understand the discourse patterns herein and be supported in using these patterns in their teaching to reflect on the nature of a discourse, and to provide guidance to students for its development. Initial versions of the discourse patterns were discussed at teacher meetings and teachers showed much interest in students discourse as a means of improving their own knowledge building work. The finalized discourse patterns was presented at a teacher conference. Teachers noted they generally saw quality discourse as emerging at random and accidentally; however, the scheme of discourse patterns enhanced their understanding of underlying principles, and offered them a means of facilitating quality online discussions that helped students avoid repetitive discourse patterns and encouraged the uptake of ideas. At a teacher professional development workshop, the G10VA class teacher shared how he had applied the discourse patterns to interpret his students' online discussions, and guide them to discuss topics more productively. We argue that if teachers can identify and know to look for knowledge-building discourse while reading online discussions, they will be better able to design and use adaptive and timely scaffolds and interventions.

The discourse pattern classifications can also be shared with students as a conceptual tool to aid in formative assessment. Studies have found that, by using tools to aid their reflection, even young students can direct their knowledge advancement processes (Chen et al. 2015) and improve the content of their discussions (Resendes et al. 2015). Ongoing research on portfolio assessment in knowledge building suggests that, with explicit criteria, students can engage in co-reflection and develop strategies to improve their online work (Lee et al. 2006; van Aalst and Chan 2007; Zhang et al. 2007; Zhang et al. 2009). As discussed, teachers' principle-based understanding of CSCL innovations is important in the enactment process. We propose that it is also important that students understand the goal of engaging in online discussions so as to encourage student agency. Introducing patterns of knowledge-construction and knowledgebuilding discourses to students may help them better understand, apart from the sharing of ideas, what they are supposed to do in their online work. As the discourse patterns indicate a developmental trajectory of knowledge-building discourse, they can be used as formative 
assessment criteria by which students can evaluate their online work. The discourse patterns may provide a means of supporting the scoring of CSCL discourse and the development of student-directed formative assessment.

\section{Methodological implications}

The study employed knowledge-building databases in the analysis of discourse patterns, and these patterns can be applicable to CSCL and online discourse. It is possible to use both qualitative coding and the identified discourse patterns to interpret signals of collaboration in CSCL discourse and to compensate for the limitations of code and count. This study enriches methodological analysis in CSCL, which usually develops analysis using small groups with short duration, and systemically explores the process of online interactions and discourse patterns in large groups in classroom settings. This study used a combination of qualitative coding and narrative analysis with a focus on the process of interactions. The coding scheme was adapted from content analysis, and the results were used in the narrative analysis for identifying discourse patterns. The patterns entailed a coarse unit that considered the sequential flow of interactions between notes. This unit of analysis is more suitable for studying group cognition (Stahl 2011) and is more aligned with the theoretical underpinnings of knowledge building. We adapted the analytical methodology using inquiry threads in knowledge building (Zhang et al. 2007), including codes, threads, and narrative units, and tested the usability of the discourse patterns by reanalyzed two additional datasets.

The findings suggested that the discourse patterns can be identified and used as a frame of reference for interpreting online discourse in other contexts, and there is preliminary evidence that with improvement in discourse patterns, there is also growth in student learning outcomes. Numerous CSCL researchers (e.g., Hmelo-Silver 2003; Puntambekar et al. 2011) have advocated the use of multiple methods to examine the nature of collaborative interactions. For example, Pifarré and Staarman (2011) used content analysis to count collaboration words, and then used qualitative analysis to interpret the nature of online discourse, using Mercer's (1996) typology of talk. Similarly, we propose that the discourse pattern identified in this study could be used in other multiple method studies as an analytic tool to develop a deeper understanding of the nature of online discourse.

\section{Limitations}

Our classification has some limitations that suggest areas for further research. The nine discourse patterns were classified within the three modes of discourse and could be considered hierarchical-i.e., knowledge building is better than knowledge construction and knowledge sharing. However, it would be useful to consider the three modes of discourse in different circumstances. As discussed elsewhere, there are many situations in which knowledge sharing is a useful mechanism for the diffusion of knowledge that is not conceptual in nature (van Aalst 2009). However, when the goal is to construct conceptual understanding or build knowledge, using knowledge sharing by itself is a poor strategy. The larger number of discourse patterns classified as knowledge sharing herein suggest that, although online discussions may begin with knowledge sharing, some discussions may be developed continually into knowledge construction and knowledge building. The mechanisms by which 
students continue to discuss and transform knowledge-sharing discourse into knowledgebuilding discourse require further research.

Second, our classification was incomplete, in part because we wanted to analyze fairly typical current attempts at knowledge building, not the most developed ones. The dataset for this study was created over a period of four to ten weeks, which is a rather short period for a community, especially when knowledge-building discourse should involve a community practice for identifying and prioritizing long-term shared goals (van Aalst 2009). While the coding dimensions of "agency," "linking," and "meta-discourse" were scarcely found in this study, they might have emerged over several months, after a more sophisticated community practice had been developed. The relationships between the seven coding dimensions and nine discourse patterns in successful knowledge-building classrooms require further research.

Finally, the study did not consider students' domain learning and content knowledge. Although the reanalysis of the Knowledge Building Teacher Network dataset provided indirect evidence that the discourse patterns were related to student learning outcomes, our main analyses excluded content knowledge. The study was entirely dedicated to investigating the process of online interactions, and was based on the theoretical assumption that knowledge-building discourse is better than knowledgesharing discourse. The relationships between discourse patterns and domain learning require further research.

\section{Conclusion}

This study developed a detailed coding scheme and a set of discourse patterns observed in online discussions in knowledge-building classrooms. The findings can be used to examine online and CSCL discourse in different platforms. Online forums often contain much knowledge sharing, and the coding scheme and discourse patterns would provide some direction and design guidance to move students towards more productive online interactions. Furthermore, the set of discourse patterns can be used to enrich knowledge-building theory by distinguishing between knowledge building and argumentation. The discourse patterns indicate a developmental trajectory of knowledge-building discourse, and can be used in teachers' professional development to help them better understand the nature of online discourse and to devise pedagogical strategies to improve the quality of students' online work. This paper takes important initial steps in proposing a classification system needed to develop strategies that teachers and students can use to evaluate and develop their online discourse, in testing the discourse patterns in different settings, and in identifying additional discourse patterns, so as to provide a framework for understanding online discourse.

Acknowledgments The data analyzed in this study were originally collected as part of a project funded by the Research Grants Council of Hong Kong awarded to the third author (Grant 740809H). The authors would like to thank the participating teachers and students for allowing us to study their students' work on Knowledge Forum.

Open Access This article is distributed under the terms of the Creative Commons Attribution 4.0 International License (http://creativecommons.org/licenses/by/4.0/), which permits unrestricted use, distribution, and reproduction in any medium, provided you give appropriate credit to the original author(s) and the source, provide a link to the Creative Commons license, and indicate if changes were made. 


\section{References}

Andriessen, J. (2006). Arguing to learn. In R. K. Sawyer (Ed.), The Cambridge handbook of the learning sciences (pp. 443-459). New York, NY: Cambridge University Press.

Arvaja, M. (2007). Contextual perspective in analysing collaborative knowledge construction of two small groups in web-based discussion. International Journal of Computer-Supported Collaborative Learning, 2(2), 133-158.

Baker, M., Andriessen, J., Lund, K., van Amelsvoort, M., \& Quignard, M. (2007). Rainbow: A framework for analysing computer-mediated pedagogical debates. International Journal of Computer-Supported Collaborative Learning, 2(2), 315-357.

Bereiter, C. (2002a). Artifacts, canons, and the progress of pedagogy: A response to contributors. In B. Smith (Ed.), Liberal education in a knowledge society (pp. 223-244). Chicago, IL: Open Court.

Bereiter, C. (2002b). Education and mind in the knowledge age. Mahwah, NJ: Lawrence Erlbaum Associates.

Bereiter, C., \& Scardamalia, M. (2003). Learning to work creatively with knowledge. In E. De Corte, L. Verschaffel, N. Entwistle, \& J. van Merrienboer (Eds.), Powerful learning environments: Unravelling basic components and dimensions (pp. 55-68). Oxford, UK: Pergamon.

Boyatzis, R. E. (1998). Transforming qualitative information: Thematic analysis and code development. Thousand Oaks: SAGE Publication.

Brown, A. L., \& Campione, J. (1996). Psychological theory and the design of innovative learning environments: On procedures, principles, and systems. In L. S. R. Glaser (Ed.), Innovations in learning: New environments for education (pp. 289-352). Mahwah, NJ: Lawrence Erlbaum Associates.

Çakır, M. P., Zemel, A., \& Stahl, G. (2009). The joint organization of interaction within a multimodal CSCL medium. International Journal of Computer-Supported Collaborative Learning, 4(2), 115-149.

Caswell, B., \& Bielaczyc, K. (2002). Knowledge forum: Altering the relationship between students and scientific knowledge. Education, Communication \& Information, 1(3), 281-305.

Chan, C. K. K. (2001). Peer collaboration and discourse patterns in learning from incompatible information. Instructional Science, 29(6), 443-479.

Chan, C. K. K. (2011). Bridging research and practice: Implementing and sustaining knowledge building in Hong Kong classrooms. International Journal of Computer-Supported Collaborative Learning, 6(2), 147-186.

Chan, C. K. K. (2012). Co-regulation of learning in computer-supported collaborative learning environments: A discussion. Metacognition and Learning, 7(1), 63-73.

Chan, C. K. K., \& Fu, E. L. F. (2011). Principle-based design for collective growth: From knowledge-sharing to explanatory knowledge-building discourse, Connecting Computer-Supported Collaborative Learning to Policy and Practice: CSCL 2011 Conference Proceedings-Long Papers, 9th International ComputerSupported Collaborative Learning Conference (Vol. 1, p. 49). China: Hong Kong.

Chan, C. K. K., \& van Aalst, J. (2006). Computer-supported collaborative knowledge building in teacher development: Experience from Hong Kong and Canadian teachers. Teaching Education, 17, 7-26.

Chan, C. K. K., Burtis, J., \& Bereiter, C. (1997). Knowledge building as a mediator of conflict in conceptual change. Cognition and Instruction, 15, 1-40.

Chen, B., \& Hong, H. Y. (2016). Schools as knowledge-building organizations: Thirty years of design research. Educational Psychologist, 51(2), 266-288.

Chen, B., Scardamalia, M., \& Bereiter, C. (2015). Advancing knowledge-building discourse through judgments of promising ideas. International Journal of Computer-Supported Collaborative Learning, 10(4), 345-366.

Chi, M. T. H. (1997). Quantifying qualitative analysis of verbal data: A practicl guide. Journal of the Learning Sciences, 6, 271-315.

Chin, C. (2007). Teacher questioning in science classrooms: Approaches that stimulate productive thinking. Journal of Research in Science Teaching, 44(6), 815-843.

Chinn, C. A., Buckland, L. A., \& Samarapungavan, A. L. A. (2011). Expanding the dimensions of epistemic cognition: Arguments from philosophy and psychology. Educational Psychologist, 46(3), 141-167.

Chuy, M., Zhang, J., Resendes, M., Scardamalia, M., \& Bereiter, C. (2011). Does contributing to a knowledge building dialogue lead to individual advancement of knowledge? In H. Spada, G. Stahl, N. Miyake, \& N. Law (Eds.), Connecting computer-supported collaborative learning to policy and practice: CSCL2011 Conference Proceedings. Volume I-long papers (pp.57-63) .International Society of the Learning Sciences

Coffey, A., \& Atkinson, P. (1996). Making sense of qualitative data: Complementary research strategies. Thousand Oaks, CA: Sage Publications.

Curriculum Development Council (2007). Liberal studies curriculum and assessment guide (secondary 4-6). Hong Kong: Curriculum Development Council.

Damsa, C. I., Kirschner, P. A., Andriessen, J. E. B., Erkens, G., \& Sins, P. H. M. (2010). Shared epistemic agency: An empirical study of an emergent construct. Journal of the Learning Sciences, 19(2), 143-186.

Dawes, L. (2004). Talk and learning in classroom science. International Journal of Science Education, 26(6), 677-695. 
de Jong, F. C. P. M., Veldhuis-Diermanse, E., \& Lutgens, G. (2002). Computer-supported collaborative learning in university and vocational education. In T. Koschmann, R. Hall, \& N. Miyake (Eds.), CSCL 2: Carrying forward the conversation (pp. 111-128). Mahwah, NJ: Lawrence Erlbaum Associates.

De Wever, B., Schellens, T., Valcke, M., \& Van Keer, H. (2006). Content analysis schemes to analyze transcripts of online asynchronous discussion groups: A review. Computers \& Education, 46(1), 6-28.

Erduran, S., Simon, S., \& Osborne, J. (2004). TAPping into argumentation: Developments in the application of Toulmin's argument pattern for studying science discourse. Science Education, 88(6), 915-933.

Erkunt, H. (2010). Emergence of epistemic agency in a college level educational technology course for preservice teachers engaged in CSCL. The Turkish Online Journal of Educational Technology, 9(3) Retrieved from http://www.tojet.net/articles/934.pdf.

Gan, Y., Scardamalia, M., Hong, H.-Y., \& Zhang, J. (2010). Early development of graphical literacy through knowledge building. Canadian Journal of Learning and Technology/La Revue Canadienne de l'Apprentissageet de la Technologie [online], 36(1), 1-28 Retrieved from http:/www.cjlt.ca/index.php/cjlt/article/view/581/284.

Greeno, J. G. (2006). Learning in activity. In R. K. Sawyer (Ed.), The Cambridge handbook of the learning sciences (pp. 79-96). New York, NY: Cambridge University Press.

Gressick, J., \& Derry, S. (2010). Distributed leadership in online groups. International Journal of ComputerSupported Collaborative Learning, 5(2), 211-236.

Guzdial, M., \& Turns, J. (2000). Effective discussion through a computer-mediated anchored forum. Journal of the Learning Sciences, 9(4), 437-469.

Hakkarainen, K. (2003a). Emergence of progressive-inquiry culture in computer-supported collaborative learning. Learning Environments Research, 6, 199-220.

Hakkarainen, K. (2003b). Progressive inquiry in a computer-supported biology class. Journal of Research in Science Teaching, 40(10), 1072-1088.

Hakkarainen, K. (2009). A knowledge-practice perspective on technology-mediated learning. International Journal of Computer-Supported Collaborative Learning, 4, 213-231.

Hakkarainen, K., \& Sintonen, M. (2002). The interrogative model of inquiry and computer-supported collaborative learning. Science \& Education, 11(1), 25-43.

Hennink, M., Hutter, I., \& Bailey, A. (2011). Qualitative research methods. Los Angeles: SAGE.

Hewitt, J. (2001). Beyond threaded discourse. International Journal of Educational Telecommunications, 7(3), $207-221$.

Hmelo-Silver, C. (2003). Analyzing collaborative knowledge construction: Multiple methods for integrating understanding. Computers \& Education, 41(4), 397-420.

Hong, H. Y., \& Sullivan, F. R. (2009). Towards an idea-centered, principle-based design approach to support learning as knowledge creation. Educational Technology Research and Development, 57, 613-627.

Hong, H. Y., Chen, F. C., Chai, C. S., \& Chan, W. C. (2011). Teacher-education students' views about knowledge building theory and practice. Instructional Science, 39(4), 467-482.

Hong, H. Y., Chen, B., \& Chai, C. S. (2016). Exploring the development of college students' epistemic views during their knowledge building activities. Computers \& Education, 98, 1-13.

Howe, C., \& Abedin, M. (2013). Classroom dialogue: A systematic review across four decades of research. Cambridge Journal of Education, 43(3), 325-356.

Järvelä, S., \& Hadwin, A. F. (2013). New Frontiers: Regulating learning in CSCL. Educational Psychologist, 48(1), 25-39.

Jeong, H., Hmelo-silver, C. E., \& Yu, Y. (2014). An examination of CSCL methodological practices and the influence of theoretical frameworks 2005-2009. International Journal of Computer-Supported Collaborative Learning, 9(3), 305-334.

King, P. M., \& Kitchener, K. S. (1994). Developing reflective judgment: Understanding and promoting intellectual growth and critical thinking in adolescents and adults. San Francisco, CA: Jossey-Bass Publishers.

Koschmann, T. (2002). Dewey's contribution to the foundations of CSCL research. In G. Stahl (Ed.), Proceedings of CSCL 2002: Foundations for a CSCL Community (pp. 17-22). Mahwah, NJ: Lawrence Erlbaum Associates.

Koschmann, T., Zemel, A., Conlee-Stevens, M., Young, N., Robbs, J., \& Barnhart, A. (2005). How do people learn? In R. Bromme, F. Hesse, \& H. Spada (Eds.), Barriers and biases in computer-mediated knowledge communication (Vol. 5, pp. 265-294). New York, NY: Springer US.

Krippendorff, K. (2004). Content analysis: An introduction to its methodology. Thousand Oaks, CA: SAGE Publications.

Kuhn, D. (2005). Education for thinking. Cambridge, MA: Harvard University Press.

Kumpulainen, K., \& Mutanen, M. (1999). The situated dynamics of peer group interaction: An introduction to an analytic framework. Learning and Instruction, 9(5), 449-473.

Laferriere, T., Lamon, M., \& Chan, C. K. K. (2006). Emerging e-trends and models in teacher education and professional development. Teaching Education, 17, 75-90.

Lahti, H., Seitamaa-Hakkarainen, P., \& Hakkarainen, K. (2004). Collaboration patterns in computer supported collaborative designing. Design Studies, 25(4), 351-371. 
Lai, M. (2009). The role of argumentation in online knowledge building activities. Hong Kong, China: The University of Hong Kong.

Lax, L., Singh, A., Scardamalia, M., \& Librach, L. (2006). Self-assessment for knowledge building in health care. QWERTY: Journal of Technology and Culture, 1(2), 19-37.

Lee, E. Y. C., Chan, C. K. K., \& van Aalst, J. (2006). Students assessing their own collaborative knowledge building. International Journal of Computer-Supported Collaborative Learning, 1(1), 57-87.

Leitao, S. (2000). The potential of argument in knowledge building. Human Development, 43(6), 332-360.

Lipponen, L., Rahikainen, M., Lallimo, J., \& Hakkarainen, K. (2003). Patterns of participation and discourse in elementary students' computer-supported collaborative learning. Learning and Instruction, 13, 487-509.

Meier, A., Spada, H., \& Rummel, N. (2007). A rating scheme for assessing the quality of computer-supported collaboration processes. International Journal of Computer-Supported Collaborative Learning, 2(1), 63-86.

Mercer, N. (1996). The quality of talk in children's collaborative activity in the classroom. Learning and Instruction, 6(4), 359-377.

Mercer, N., \& Littleton, K. (2007). Dialogue and the development of children's thinking. London: Routledge.

Moss, J., \& Beatty, R. (2006). Knowledge building in mathematics: Supporting collaborative learning in pattern problems. International Journal of Computer-Supported Collaborative Learning, 1, 441-465.

Moss, J., \& Beatty, R. (2010). Knowledge building and mathematics: Shifting the responsibility for knowledge advancement and engagement. Canadian Journal of Learning and Technology/La Revue Canadienne de l'Apprentissageet de la Technologie [online], 36(1), 1-33 Retrieved from http://www.cjlt.ca/index. $\mathrm{php} / \mathrm{cjlt} / \mathrm{article} / \mathrm{view} / 575 / 277$.

Mu, J., Stegmann, K., Mayfield, E., Rosé, C., \& Fischer, F. (2012). The ACODEA framework: Developing segmentation and classification schemes for fully automatic analysis of online discussions. International Journal of Computer-Supported Collaborative Learning, 7(2), 285-305.

Mylopoulos, M., \& Scardamalia, M. (2008). Doctors' perspectives on their innovations in daily practice: Implications for knowledge building in health care. Medical Education, 42, 975-981.

Niu, H., \& van Aalst, J. (2009). Participation in knowledge-building discourse: An analysis of online discussions in mainstream and honours social studies courses. Canadian Journal of Learning and Technology, 35(1) Retrieved from http://cjlt.csj.ualberta.ca/index.php/cjlt/article/viewArticle/515.

Osborne, J. F., \& Patterson, A. (2011). Scientific argument and explanation: A necessary distinction? Science Education, 95(4), 627-638.

Palmer, S., Holt, D., \& Bray, S. (2008). Does the discussion help? The impact of a formally assessed online discussion on final student results. British Journal of Educational Technology, 39(5), 847-858.

Peters, V. L., \& Hewitt, J. (2010). An investigation of student practices in asynchronous computer conferencing courses. Computers \& Education, 54(4), 951-961.

Phielix, C., Prins, F. J., \& Kirschner, P. A. (2010). Awareness of group performance in a CSCL-environment: Effects of peer feedback and reflection. Computers in Human Behavior, 26(2), 151-161.

Pifarré, M., \& Staarman, J. K. (2011). Wiki-supported collaborative learning in primary education: How a dialogic space is created for thinking together. International Journal of Computer-Supported Collaborative Learning, 6(2), 187-205.

Polkinghorne, D. E. (1988). Narrative knowing and the human sciences. Albany, NY: State University of New York Press.

Polkinghorne, D. E. (1995). Narrative configuration in qualitative analysis. International Journal of Qualitative Studies in Education, 8(1), 5-23.

Puntambekar, S., Erkens, G., \& Hmelo-Silver, C. E. (2011). Introduction. Analyzing Interactions in CSCL Methods, Approaches and Issues, 12, ix-xvii.

Resendes, M., Scardamalia, M., Bereiter, C., Chen, B., \& Halewood, C. (2015). Group-level formative feedback and metadiscourse. International Journal of Computer-Supported Collaborative Learning, 10(3), 309-336.

Riessman, C. K. (2008). Narrative methods for the human sciences. Los Angeles, CA: Sage Publications.

Roschelle, J., \& Teasley, S. D. (1994). The construction of shared knowledge in collaborative problem solving. NATO ASI Series Computer and Systems Sciences, 128, 69-97.

Roth, W. M. (2005). Doing qualitative research: Praxis of method. Rotterdam, Taipei: Sense Publishers.

Rourke, L., Anderson, T., Garrison, D. R., \& Archer, W. (1999). Assessing social presence in asynchronous textbased computer. Journal of Distance Education, 14(2), 50-71.

Rummel, N., Spada, H., \& Hauser, S. (2009). Learning to collaborate while being scripted or by observing a model. International Journal of Computer-Supported Collaborative Learning, 4(1), 69-92.

Saldaña, J. (2009). The coding manual for qualitative researchers. Los Angeles, CA: Sage Publications.

Scardamalia, M. (2002). Collective cognitive responsibility for the advancement of knowledge. In B. Smith (Ed.), Liberal education in a knowledge society (pp. 67-98). Chicago, IL: Open Court.

Scardamalia, M. (2004). CSILE/knowledge forum. In A. Kovalchick\& K. Dawson (Eds.), Education and technology: An encyclopedia (pp. 183-192). Santa Barbara, CA: ABC-CLIO. 
Scardamalia, M., \& Bereiter, C. (1993). Computer support for knowledge-building communities. The Journal of the Learning Sciences, 3(3), 265-283.

Scardamalia, M., \& Bereiter, C. (2006). Knowledge building: Theory, pedagogy, and technology. In R. K. Sawyer (Ed.), The Cambridge handbook of the learning sciences (pp. 97-115). New York: Cambridge University Press.

Scardamalia, M., \& Bereiter, C. (2010). A brief history of knowledge building. Canadian Journal of Learning and Technology/La Revue Canadienne de l'Apprentissageet de la Technologie [online], 36(1), 1-16 Retrieved from http:/www.cjlt.ca/index.php/cjlt/article/view/574/276.

Scardamalia, M., \& Bereiter, C. (2014). Knowledge building and knowledge creation: Theory, pedagogy, and technology. In R. K. Sawyer (Ed.), The Cambridge handbook of the learning sciences (pp. 397-417). New York: Cambridge University Press.

Scardamalia, M., Bereiter, C., Hewitt, J., \& Webb, J. (1996). Constructive learning from texts in biology. In K. M. Fischer \& M. Kirby (Eds.), Relations and biology learning: The acquisition and use of knowledge structures in biology (pp. 44-64). Berlin, Germany: Springer-Verlag.

Scheuer, O., Loll, F., Pinkwart, N., \& McLaren, B. (2010). Computer-supported argumentation: A review of the state of the art. International Journal of Computer-Supported Collaborative Learning, 5(1), 43-102.

Schommer, M. (1990). Effects of beliefs about the nature of knowledge on comprehension. Journal of Educational Psychology, 82, 498-504.

Schrire, S. (2006). Knowledge building in asynchronous discussion groups: Going beyond quantitative analysis. Computers \& Education, 46(1), 49-70.

Schwartz, D. L. (1995). The emergence of abstract representations in dyad problem solving. Journal of the Learning Sciences, 4(3), 321-354.

Seitamaa-Hakkarainen, P., Raunioi, A. M., Raami, A., Muukkonen, H., \& Hakkarainen, K. (2001). Computer support for collaborative designing. International Journal of Technology and Design Education, 11(2), 181202.

Siqin, T., van Aalst, J., \& Chu, S. K. W. (2015). Fixed group and opportunistic collaboration in a CSCL environment. International Journal of Computer-Supported Collaborative Learning, 10(2), 161-181.

Stahl, G. (2002). Rediscovering CSCL. In T. Koschmann, R. Hall, \& N. Miyake (Eds.), CSCL 2: Carrying forward the conversation (pp. 169-181). Mahwah, NJ: Lawrence Erlbaum Associates.

Stahl, G. (2003). Group cognition: Computer support for building collaborative knowledge. Cambridge, MA: MIT Press.

Stahl, G. (2007). CSCL and its flash themes. International Journal of Computer-Supported Collaborative Learning, 2(4), 359-362.

Stahl, G. (2011). How to study group cognition. Analyzing Interactions in CSCL Methods, Approaches and Issues, 12, 107-130.

Stahl, G., Koschmann, T., \& Suthers, D. (2006). Computer-supported collaborative learning. In R. K. Sawyer (Ed.), The Cambridge handbook of the learning sciences (pp. 409-423). New York: Cambridge University Press.

Stegman, K., Weinberger, A., \& Fischer, F. (2007). Facilitating argumentative knowledge construction with computer-supported collaboration scripts. International Journal of Computer-Supported Collaborative Learning, 2, 421-447.

Strijbos, J.-W., Martens, R. L., Prins, F. J., \& Jochems, W. M. G. (2006). Content analysis: What are they talking about? Computers \& Education, 46(1), 29-48.

Sun, Y., Zhang, J., \& Scardamalia, M. (2010). Knowledge building and vocabulary growth over two years, grades 3 and 4. Instructional Science, 38, 147-171.

Suthers, D. (2006). A qualitative analysis of collaborative knowledge construction through shared representations. Research and Practice in Technology Enhanced Learning, 1(2), 1-28.

Suthers, D., \& Medina, R. (2011). Tracing interaction in distributed collaborative learning. Analyzing Interactions in CSCL Methods, Approaches and Issues, 12, 341-366.

Suthers, D., Dwyer, N., Medina, R., \& Vatrapu, R. (2010). A framework for conceptualizing, representing, and analyzing distributed interaction. International Journal of Computer-Supported Collaborative Learning, 5(1), 5-42.

ten Have, P. (2007). Doing conversation analysis (2nd ed.). Los Angeles: Sage.

van Aalst, J. (2009). Distinguishing knowledge-sharing, knowledge-construction, and knowledge-creation discourses. International Journal of Computer-Supported Collaborative Learning, 4, 259-287.

van Aalst, J., \& Chan, C. K. K. (2007). Student-directed assessment of knowledge building using electronic portfolios. The Journal of the Learning Sciences, 16, 175-220.

van Aalst, J., \& Truong, M. S. (2011). Promoting knowledge-creation discourse in an Asian primary five classroom: Results from an inquiry into life cycles. International Journal of Science Education, 33(4), 487515 . 
Wegerif, R. (1998). The social dimension of asynchronous learning networks. Journal of Asynchronous Learning Networks, 2(1), $34-49$.

Weinberger, A., \& Fischer, F. (2006). A framework to analyze argumentative knowledge construction in computer-supported collaborative learning. Computers\& Education, 46(1), 71-95.

Wise, A., \& Chiu, M. (2011). Analyzing temporal patterns of knowledge construction in a role-based online discussion. International Journal of Computer-Supported Collaborative Learning, 6(3), 445-470.

Wise, A., Hausknecht, S. N., \& Zhao, Y. (2014). Attending to others' posts in asynchronous discussions: Learners' online "listening" and its relationship to speaking. International Journal of ComputerSupported Collaborative Learning, 9(2), 185-209.

Zhang, J. (2010). Technology-supported learning innovation in cultural contexts. [review]. Educational Technology Research and Development, 58(2), 229-243.

Zhang, J., \& Sun, Y. (2011). Reading for idea advancement in a grade 4 knowledge building community. Instructional Science, 39, 429-452.

Zhang, J., Scardamalia, M., Lamon, M., Messina, R., \& Reeve, R. (2007). Socio-cognitive dynamics of knowledge building in the work of 9- and 10-year-olds. Educational Technology Research \& Development, 55(2), 117-145.

Zhang, J., Scardamalia, M., Reeve, R., \& Messina, R. (2009). Designs for collective cognitive responsibility in knowledge-building communities. Journal of the Learning Sciences, 18(1), 7-44.

Zhang, J., Hong, H.-Y., Scardamalia, M., Teo, C. L., \& Morley, E. A. (2011). Sustaining knowledge building as a principle-based innovation at an elementary school. Journal of the Learning Sciences, 20(2), 262-307. 